Published in final edited form as:

Nat Immunol. 2014 May ; 15(5): 439-448. doi:10.1038/ni.2864.

\title{
CD4+ $T$ cell lineage integrity is controlled by the histone deacetylases HDAC1 and HDAC2
}

\author{
Nicole Boucheron ${ }^{\# 1}$, Roland Tschismarov ${ }^{\# 1}$, Lisa Goeschl ${ }^{1,2}$, Mirjam A. Moser ${ }^{3}$, Sabine \\ Lagger $^{3,4}$, Shinya Sakaguchi ${ }^{1}$, Mircea Winter ${ }^{3}$, Florian Lenz ${ }^{5}$, Dijana Vitko ${ }^{6}$, Florian P. \\ Breitwieser $^{6}$, Lena Müller ${ }^{1}$, Hammad Hassan ${ }^{1}$, Keiryn L. Bennett ${ }^{6}$, Jacques Colinge ${ }^{6}$, \\ Wolfgang Schreiner ${ }^{5}$, Takeshi Egawa ${ }^{7}$, Ichiro Taniuchi ${ }^{8}$, Patrick Matthias ${ }^{9}$, Christian \\ Seiser $^{3,11}$, and Wilfried Ellmeier ${ }^{1,11}$
}

${ }^{1}$ Division of Immunobiology, Institute of Immunology, Center for Pathophysiology, Infectiology and Immunology, Medical University of Vienna, A-1090 Vienna, Austria 2Division of Rheumatology, Medicine III, Medical University of Vienna, 1090 Vienna, Austria ${ }^{3}$ Department of Medical Biochemistry, Max F. Perutz Laboratories, Vienna Biocenter, Medical University of Vienna, 1030 Vienna, Austria ${ }^{5}$ Division of Biosimulation and Bioinformatics, Center for Medical Statistics, Informatics, and Intelligent Systems, Medical University of Vienna, 1090 Vienna, Austria ${ }^{6} \mathrm{CeMM}$ Research Center for Molecular Medicine of the Austrian Academy of Sciences, 1090 Vienna, Austria ${ }^{7}$ Department of Pathology \& Immunology, Washington University School of Medicine, St. Louis, MO 63110, USA ${ }^{8}$ Laboratory for Transcriptional Regulation, RIKEN Center for Integrative Medical Sciences (IMS-RCAI), Yokohama, Kanagawa 230-0045, Japan ${ }^{9}$ Friedrich Miescher Institute for Biomedical Research, Novartis Research Foundation, 4058 Basel, Switzerland and University of Basel, Faculty of Sciences, 4051 Basel, Switzerland

\# These authors contributed equally to this work.

\begin{abstract}
Molecular mechanisms that maintain lineage integrity of helper $\mathrm{T}$ cells are largely unknown. Here we show histone deacetylases (HDAC) 1 and 2 as crucial regulators of this process. Loss of HDAC1 and HDAC2 during late T cell development led to the appearance of MHC class II-
\end{abstract}

\footnotetext{
Users may view, print, copy, and download text and data-mine the content in such documents, for the purposes of academic research, subject always to the full Conditions of use:http://www.nature.com/authors/editorial_policies/license.html\#terms

${ }^{11}$ C.S. and W.E. are equal corresponding authors. Correspondence should be addressed to W.E. (wilfried.ellmeier@meduniwien.ac.at) or to C.S. (christian.seiser@meduniwien.ac.at).

${ }^{4}$ Current address: University of Edinburgh, Wellcome Trust Centre for Cell Biology, Edinburgh EH9 3JR, United Kingdom. AUTHOR CONTRIBUTIONS

N.B., R.T., C.S. and W.E. designed the research; N.B., R.T. performed most of the experiments and analyzed the data; L.G., S.L. M.W., L.M. and H.H. performed some of the experiments and analyzed data; S.S. designed some of the research and analyzed data; M.A.M. performed ChIP assays and analyzed data; F.L. and W.S. analyzed microarray data, T.E. provided experimental data and reagents, I.T., P.M. provided reagents and mice; K.L.B and D.V. designed and performed the mass spectrometric experiments; F.P.B. and J.C. performed analysis of the proteomic data set and cross correlation with the microarray data; N.B., R.T., C.S. and W.E. wrote the manuscript.

Accession codes.

Microarray data: ArrayExpress database E-MTAB-2184.

Proteomic data: PeptideAtlas PASS00448.

COMPETING FINANCIAL INTERESTS

The authors declare no competing financial interest.
} 
selected $\mathrm{CD} 4^{+}$helper $\mathrm{T}$ cells $\left(\mathrm{T}_{\mathrm{H}}\right)$ that expressed CD8 lineage genes such as $C d 8 a$ and $C d 8 b 1$. HDAC1-HDAC2-deficient $\mathrm{T}_{\mathrm{H}} 0$ and $\mathrm{T}_{\mathrm{H}} 1$ cells further up-regulated $C d 8$ lineage genes and acquired a CD8 effector program in a manner dependent on Runx-CBF $\beta$ complexes, while $\mathrm{T}_{\mathrm{H}} 2$ cells repressed CD8 lineage features independently of HDAC1 and HDAC2. These results demonstrate that HDAC1-HDAC2 maintain CD4 lineage integrity by repressing Runx-CBF $\beta$ complexes that otherwise induce a CD8-like effector program in $\mathrm{CD}^{+} \mathrm{T}$ cells.

Dynamic changes in the acetylation of core histones play a key role in the regulation of gene expression during development and differentiation. Modification of core histones by lysine acetylation is controlled by histone acetyltransferases (HATs) and histone deacetylases (HDACs), which are major epigenetic regulators. Eighteen histone deacetylases grouped in 4 classes have been identified in mammalian organisms. These HDAC subgroups differ in their structure, tissue expression, intracellular localization and target specificity. Class I is comprised of HDAC1, 2, 3 and 8, while the class II group, which is subdivided into class IIa and class IIb, includes HDAC4, 5, 6, 7, 9 and 10. HDAC11 is the only member representing class IV HDACs. The class III group of HDACs is comprised of sirtuins (Sirt1-7), which differ in their co-factor requirement for enzymatic activity 1,2 .

The usage of HDAC inhibitors revealed important immunological processes dependent on HDAC activity, and several mammalian deacetylases, including HDAC1, HDAC2, HDAC3, HDAC7 and HDAC9 have been implicated in regulating T cell development and function ${ }^{3-5}$. Nevertheless, unique functions of individual HDAC members in specific T cell functions are still only poorly understood. T cell-specific loss of HDAC1 (using a $C d 4$-Cre deletion) leads to enhanced allergic airway inflammation and increased $\mathrm{T}_{\mathrm{H}} 2$ cytokine production, while $\mathrm{T}$ cell development was not impaired in these mice ${ }^{6}$. However, HDAC2 was up-regulated in the absence of HDAC1, thus compensatory pathways or functions between these two closely related class I HDAC family members could occur in T cells, as described for several other cell systems ${ }^{7-10}$. Indeed, mice with an $L c k$-Cre-mediated T cellspecific combined deletion of HDAC1 and HDAC2 displayed severely reduced thymic cellularity, accompanied by a block at the double-negative (DN) to double-positive (DP) transition ${ }^{11,12}$. A block at the pro-pre-B to pre-B transition during $\mathrm{B}$ cell development was also observed following the B cell-specific loss of HDAC1 and HDAC2 ${ }^{10}$. Interestingly, mice with a reduced combined activity of HDAC1-HDAC2 (i.e. both Hdacl alleles and one $H d a c 2$ allele deleted) undergo neoplastic transformation of immature thymocytes. These tumor cells become aneuploid and display enhanced expression of c-Myc ${ }^{11,12}$. Together, this indicates that HDAC1 and HDAC2 are essential for early T cell development and the control of genomic stability in immature $\mathrm{T}$ cells.

Here we investigated the role of HDAC1 and HDAC2 at later stages during T cell development. We show that $C d 4$-Cre-mediated T cell-specific loss of HDAC1 and HDAC2 led to the appearance of MHC class II-selected $\mathrm{CD}^{+}$helper T cells that spontaneously expressed CD8 lineage genes such as $C d 8 a, C d 8 b 1$ and Eomes (encoding for Eomesodermin). HDAC1-HDAC2-deficient $\left(\mathrm{Hdacl}^{\mathrm{f} / \mathrm{f}} \mathrm{Hdac} 2^{\mathrm{f} / \mathrm{f}} \mathrm{Cd} 4\right.$-Cre, designated as HDAC1-2 cKO) CD4 lineage T cells had normal expression of Th-POK protein under homeostatic conditions and up-regulated CD154 upon activation, thus displaying 
characteristic features of helper T cells. However, activated HDAC1- 2 cKO CD4 ${ }^{+} \mathrm{T}$ cells acquired CD8 effector features, indicated by a strong further up-regulation of Eomesodermin, by high production of IFN- $\gamma$ and by the increased expression of Runx3, Tbet, Granzyme B and Perforin. The expression of CD8 effector genes in activated HDAC1-2 cKO CD $4^{+} \mathrm{T}$ cells required Runx-CBF $\beta$ and correlated with the presence of Runx-CBF $\beta$ complexes and local histone hyperacetylation at the promoter regions of these genes. These observations revealed that HDAC1 and HDAC2 are essential to maintain CD4 lineage integrity by repressing $\mathrm{CD} 8$ lineage genes in $\mathrm{CD} 4^{+} \mathrm{T}$ cells.

\section{Results}

\section{Appearance of $\mathrm{CD}^{+}{ }^{+} \mathrm{CD}^{+} \mathrm{T}$ cells in $\mathrm{Hdac1}^{\mathrm{f} / \mathrm{f}} \mathrm{Hdac2}^{\mathrm{f} / \mathrm{f}} \mathrm{Cd} 4-\mathrm{Cre}$ mice}

To investigate redundant and non-redundant functions of HDAC1 and HDAC2, we generated mice with a conditional T cell-specific (using $C d 4$-Cre) combined loss of HDAC1 and HDAC2. Similar to $\mathrm{Hdacl}^{\mathrm{f} / \mathrm{f}} \mathrm{Cd} 4$-Cre mice ${ }^{6}, \mathrm{Hdac}^{\mathrm{f} / \mathrm{f}} \mathrm{Cd}$-Cre (labeled as HDAC2 cKO throughout the manuscript) mice did not display developmental alterations in the thymus and had normal $\mathrm{CD}^{+}$and $\mathrm{CD}^{+} \mathrm{T}$ cell numbers in the spleen (data not shown). HDAC2 protein was progressively lost during $\mathrm{T}$ cell development and was not detectable in peripheral HDAC2 cKO T cells, showing efficient deletion (Supplementary Fig. 1a-c). Naïve and effector T cells, as well as Foxp $3^{+}$regulatory $\mathrm{T}$ cells were present at normal numbers (Supplementary Fig. 1d,e), indicating normal T cell homeostasis, although HDAC1 was up-regulated in the absence of HDAC2 (Supplementary Fig. 1f).

Hdac $1^{\mathrm{f} / \mathrm{f}} \mathrm{Hdac} 2^{\mathrm{f} / \mathrm{f}} \mathrm{Cd} 4$-Cre (designated as HDAC1-2 cKO throughout the manuscript) mice displayed a 2-3-fold reduction of peripheral T cell numbers (Fig. 1a,b). However, a significant population of $\mathrm{CD}^{+}{ }^{+} \mathrm{CD} 8{ }^{+}$double-positive peripheral $\mathrm{T}$ cells (up to $16 \%$ ) was present in HDAC1-2 cKO mice (Fig. 1a). These $\mathrm{CD} 4^{+} \mathrm{CD} 8^{+} \mathrm{T}$ cells expressed CD8a $\beta$ heterodimers (Fig. 1c) with similar TCR $\beta$ and reduced CD4 expression compared to wildtype $\mathrm{CD}^{+}{ }^{+} \mathrm{T}$ cells (Supplementary Fig. 2a,b). In addition, a fraction of Foxp $3^{+} \mathrm{HDAC} 1-2$ cKO CD4 ${ }^{+}$T cells (approx. 3-4\%) also expressed CD8 (Supplementary Fig. 2c). The percentage of $\mathrm{CD} 44^{\mathrm{hi}} \mathrm{CD} 4^{+}$and $\mathrm{CD} 8^{+} \mathrm{T}$ cells was not significantly changed in HDAC1-2 cKO mice (Supplementary Fig. 2d). However, CD44 ${ }^{\text {hi }}$ subsets within the $\mathrm{CD} 4^{+} \mathrm{CD} 8^{+} \mathrm{T}$ cell population were reduced (approx. 2.6 to 3 -fold) compared to $\mathrm{CD} 4^{+}$and $\mathrm{CD} 8^{+} \mathrm{T}$ cells in HDAC1-2 cKO mice (Supplementary Fig. 2d). Upon ex vivo short-term activation HDAC1-2 cKO CD $4^{+} \mathrm{CD} 8^{+} \mathrm{T}$ cells displayed a cytokine profile characteristic of naïve cells (Supplementary Fig. 2e,f) and did not show up-regulation of memory markers under homeostatic conditions (Supplementary Fig. 2g). This suggests that HDAC1-2 cKO $\mathrm{CD} 4^{+} \mathrm{CD} 8^{+} \mathrm{T}$ cells are naïve $\mathrm{T}$ cells. HDAC1-2 $\mathrm{cKO}$ mice displayed an approx. 1.6-fold enhanced Annexin $\mathrm{V}^{+}$fraction of peripheral $\mathrm{CD} 8^{+} \mathrm{T}$ cells, while there was no change within the $\mathrm{CD}^{+} \mathrm{T}$ cell population (Fig. 1d,e). Moreover, HDAC1- 2 CKO CD4 ${ }^{+} \mathrm{CD} 8^{+} \mathrm{T}$ cells displayed a similar percentage of Annexin $\mathrm{V}^{+}$cells as the $\mathrm{CD}^{+} \mathrm{T}$ cell subset (Fig. 1d,e). Together, this indicates that loss of HDAC1 and HDAC2 leads to reduced peripheral $\mathrm{T}$ cell numbers and to the appearance of $\mathrm{CD} 4^{+} \mathrm{CD} 8^{+} \mathrm{T}$ cells.

A detailed analysis of thymocyte subsets in HDAC1-2 cKO mice showed normal total $\mathrm{CD} 4 \mathrm{SP}$ or CD8SP thymocyte numbers as well as normal percentages and numbers of 
TCR $\beta^{\text {hi }}$ cells (Fig. 2a-d). Expression of CD5, CD69 and CD24 in HDAC1-2 cKO DP thymocytes was similar to WT DP thymocytes, and TCR $\beta^{\text {hi }}$ SP cells up-regulated CD5 normally, indicating no major alteration in TCR signaling during positive selection (Fig. 2a). However, the percentage and numbers of $\mathrm{TCR} \beta{ }^{\text {hi }} \mathrm{CD} 24^{\mathrm{lo}}$ cells were approx. $70 \%$ reduced in HDAC1-2 cKO mice, while the number of TCR $\beta^{\text {hi }} \mathrm{CD} 24^{\text {hi }}$ cells was similar to WT mice (Fig. 2a,c,d). There was also a mild reduction of the percentage of CD69 ${ }^{+} \mathrm{CD} 8 \mathrm{SP}$ cells (data not shown). Mature HDAC1-2 cKO TCR $\beta^{\text {hi }} \mathrm{CD} 24^{\text {lo }}$ thymocytes contained a significant $\mathrm{CD} 4{ }^{+} \mathrm{CD} 8{ }^{+} \mathrm{T}$ cell population (up to $7 \%$ ) in addition to regular CD4SP and CD8 SP thymocytes (Fig. 2e), indicating that $\mathrm{CD} 4^{+} \mathrm{CD} 8^{+} \mathrm{T}$ cells are emerging already during $\mathrm{T}$ cell development. In vivo BrdU labeling experiments showed that the frequency of $\mathrm{BrdU}^{+}$ TCR $\beta^{\text {hi }}{ }^{\mathrm{CD}} 24^{\text {lo }}$ thymocytes was similar in WT and HDAC1-2 cKO thymi (Fig. 2f), while the percentage of Annexin $\mathrm{V}^{+} \mathrm{TCR} \beta{ }^{\text {hi }} \mathrm{CD} 24^{\text {lo }}$ was approx. 1.4-fold increased (although not statistically significant) in HDAC1-2 cKO mice compared to wild-type (Fig. 2g). This suggests a partial loss of TCR $\beta{ }^{\text {hi }} \mathrm{CD} 24^{\text {lo }}$ cells due to apoptosis rather than a developmental block at the $\mathrm{CD} 24^{\mathrm{hi}}$ to $\mathrm{CD} 24^{\mathrm{lo}}$ transition. Moreover, the generation of either wild-type $\left(\mathrm{CD} 45.1^{+}\right)$and WT $\left(\mathrm{CD} 45.2^{+}\right)$or wild-type $\left(\mathrm{CD} 45.1^{+}\right)$and HDAC1-2 $\mathrm{cKO}\left(\mathrm{CD} 45.2^{+}\right)$ mixed bone marrow (BM) chimeric mice indicated that the reduction in $\mathrm{T}$ cell numbers and the appearance of $\mathrm{CD} 4^{+} \mathrm{CD} 8^{+} \mathrm{T}$ cells are cell-intrinsic effects (Supplementary Fig. 3a).

Taken together, the data indicate $\mathrm{T}$ cell-intrinsic defects in HDAC1-2 $\mathrm{cKO}$ mice that lead to reduced $\mathrm{T}$ cell numbers and the appearance of peripheral $\mathrm{CD} 4^{+} \mathrm{CD} 8^{+} \mathrm{T}$ cells.

\section{HDAC1-2 cKO CD4+CD8 ${ }^{+} \mathrm{T}$ cells are helper T cells}

To test whether $\mathrm{HDAC} 1-2 \mathrm{cKO} \mathrm{CD} 4^{+} \mathrm{CD} 8^{+} \mathrm{T}$ cells, like $\mathrm{CD} 4^{+} \mathrm{T}$ cells, were selected on MHC class II, we generated MHC class I-deficient $\left(B 2 m^{-/}\right)$WT or HDAC1-2 cKO BM chimeric mice. WT BM chimeric $B 2 \mathrm{~m}^{-/-}$mice developed peripheral $\mathrm{CD} 4^{+} \mathrm{T}$ cells but not $\mathrm{CD}^{+} \mathrm{T}$ cells in the absence of MHC class I (Fig. 3a). In HDAC1-2 cKO chimeric $B 2 \mathrm{~m}^{-/-}$ mice both $\mathrm{CD}^{+}{ }^{+} \mathrm{T}$ cells and $\mathrm{CD} 4^{+} \mathrm{CD} 8^{+}$peripheral $\mathrm{T}$ cell subsets developed (Fig. 3a), while both subsets were absent or markedly reduced in HDAC1-2 cKO mice that have been crosses onto a MHC class II-deficient $\left(H 2-\mathrm{Abl}^{-/-}\right)$background (Fig. $3 \mathrm{~b}$ ). These results indicated that the peripheral $\mathrm{CD} 4^{+} \mathrm{CD} 8^{+} \mathrm{T}$ cells in HDAC1-2 $\mathrm{cKO}$ were MHC class IIrestricted (Fig. 3a). Moreover, the $\mathrm{CD} 4^{+} \mathrm{CD} 8^{+} \mathrm{T}$ cells isolated from HDAC1-2 $\mathrm{cKO}$ chimeric $B 2 m^{-/-}$mice or from HDAC1-2 cKO mice up-regulated CD154 upon activation (Fig. 3c, Supplementary Fig. 3b), thus displaying helper lineage features.

Only a fraction of the HDAC1-2 cKO CD4 ${ }^{+} \mathrm{T}$ cells up-regulated CD8 under homeostatic conditions in vivo. Inefficient deletion and thus escape of cells that retained $\mathrm{Hdacl}$ and/or $H d a c 2$ alleles was excluded, because a PCR analysis revealed that the majority of cells (> 95\%) had deleted Hdacl and Hdac2 alleles (Supplementary Fig. 3c). Intracellular staining showed that $>99 \%$ of wild-type $\mathrm{CD} 4^{+} \mathrm{T}$ cells expressed high amounts of HDAC 1 and HDAC2 (Fig. 3d). In HDAC1-2 $\mathrm{cKO} \mathrm{CD} 4^{+} \mathrm{T}$ cells, residual HDAC1 and HDAC2 protein expression was still detectable (Fig. 3d,e). However, the percentage of HDAC1 and HDAC2 expressing cells (by approx. 50\%), as well as the amounts of HDAC1 and HDAC2 protein were reduced (by approx. $60 \%$ ) in HDAC1- 2 cKO CD4 ${ }^{+} \mathrm{T}$ cells compared to $\mathrm{WT} \mathrm{CD} 4^{+} \mathrm{T}$ cells (Fig. 3e,f) and even further reduced (by approx. 25-30\%) in HDAC1-2 cKO 
$\mathrm{CD} 4^{+} \mathrm{CD} 8^{+} \mathrm{T}$ cells compared to HDAC1-2 $\mathrm{cKO} \mathrm{CD} 4^{+} \mathrm{T}$ cells (Fig. 3f). This indicates a slow disappearance of HDAC1 and HDAC2 proteins upon $C d 4$-Cre-mediated deletion of the $H d a c 1$ and $H d a c 2$ alleles.

Together, these data indicate that peripheral HDAC1-2 $\mathrm{cKO} \mathrm{CD} 4^{+} \mathrm{CD} 8^{+} \mathrm{T}$ cells represent helper lineage $\mathrm{T}$ cells and further show that the up-regulation of CD8 in HDAC1-2 cKO CD4 lineage T cells under homeostatic conditions inversely correlated with the decreasing amounts of HDAC1 and HDAC2 protein upon deletion of Hdacl and Hdac2 alleles.

\section{Activated HDAC1-2 cKO CD4+ T cells up-regulate CD8}

Next, we tested whether CD8 is stably silenced in HDAC1-2 cKO CD4 ${ }^{+} \mathrm{T}$ cells that did not up-regulate $\mathrm{CD} 8$ in vivo. Sorted WT and HDAC1-2 cKO CD4 ${ }^{+} \mathrm{T}$ cells showed a similar proliferative response (Fig. 4a) and up-regulation of CD25 and CD69 (Fig. 4b) to anti-CD3 and anti-CD28 stimulation, suggesting that early $\mathrm{T}$ cell activation pathways are not altered in the absence of HDAC1 and HDAC2. A large proportion (up to 45\%) of HDAC1-2 cKO $\mathrm{CD}^{+} \mathrm{T}$ cells up-regulated CD8 (Fig. 4c) while control WT CD4 ${ }^{+} \mathrm{T}$ cells (Fig. 4c) or single $\mathrm{Hdacl}^{\mathrm{f} / \mathrm{f}} \mathrm{Cd} 4$-Cre or $\mathrm{Hdac2}{ }^{\mathrm{f} / \mathrm{f}} \mathrm{Cd} 4$-Cre $\mathrm{CD} 4{ }^{+} \mathrm{T}$ cells (data not shown) remained CD8negative. Of note, HDAC1-2 cKO CD8 ${ }^{+} \mathrm{T}$ cells did not up-regulate CD4 (Fig. 4c). The upregulation of CD8 expression was not potentiated by TGF $\beta$ (data not shown), which is known to induce $\mathrm{CD} 8$ expression on a fraction of $\mathrm{CD} 4^{+} \mathrm{T}$ cells ${ }^{13}$. Because the $\mathrm{Cd} 8$ enhancer $\mathrm{E} 8_{\mathrm{I}}$ directs $\mathrm{CD} 8$ expression in mature $\mathrm{CD} 8^{+} \mathrm{T}$ cells ${ }^{14-16}$, we tested whether $\mathrm{E} 8_{\mathrm{I}}$ is required for $\mathrm{CD} 8$ expression in $\mathrm{HDAC} 1-2 \mathrm{cKO} \mathrm{CD} 4{ }^{+} \mathrm{CD} 8{ }^{+} \mathrm{T}$ cells. In comparison to $\mathrm{E}_{\mathrm{I}}{ }^{+/+} \mathrm{HDAC} 1-2 \mathrm{cKO}$ mice, $\mathrm{CD} 4^{+} \mathrm{CD} 8^{+} \mathrm{T}$ cell numbers were reduced by approx. $50 \%$ and these cells had lower CD8 expression (approx. 30\% less MFI) in E8 ${ }^{-1-} \mathrm{HDAC} 1-2 \mathrm{cKO}$ mice (Fig. 4d-f). Moreover, ex vivo activated $\mathrm{E}_{\mathrm{I}}{ }^{-/} \mathrm{HDAC} 1-2 \mathrm{cKO} \mathrm{CD}^{+}{ }^{+} \mathrm{T}$ cells showed impaired up-regulation of $\mathrm{CD} 8$ in comparison to activated $\mathrm{E}_{\mathrm{I}}{ }^{+/+} \mathrm{HDAC} 1-2 \mathrm{cKO} \mathrm{CD} 4^{+} \mathrm{T}$ cells (Supplementary Fig. 3d). These data indicate de-repression of $C d 8$ in all HDAC1-2 cKO CD4 lineage T cells and show that CD8 expression in HDAC1-HDAC2-deficient CD4 lineage $\mathrm{T}$ cells is largely dependent on $\mathrm{E} 8_{\mathrm{I}}$.

\section{HDAC1-2 cKO CD4+ $T$ cells acquire CD8 effector features}

To further characterize HDAC1-2 $\mathrm{cKO} \mathrm{CD} 4^{+}$and $\mathrm{CD} 4^{+} \mathrm{CD} 8^{+} \mathrm{T}$ cell subsets, we analyzed gene expression using Agilent arrays. 450 genes were up- and 162 genes were downregulated in HDAC1-2 $\mathrm{cKO} \mathrm{CD}^{+} \mathrm{T}$ cells compared to $\mathrm{WT} \mathrm{CD}^{+} \mathrm{T}$ cells (Supplementary Fig. $4 \mathrm{a}, \mathrm{b}$ and Supplementary Table 1). Moreover, the up-regulation of $C d 8 a$ and $C d 8 b 1$ in HDAC1-2 $\mathrm{cKO} \mathrm{CD} 4^{+} \mathrm{CD} 8^{+} \mathrm{T}$ cells was accompanied by the enhanced expression of Eomes (encoding Eomesodermin) (5.4-fold), Runx3 (1.9-fold) and Tbx21 (encoding T-bet) (3.6fold) (Supplementary Fig. 4c,d), which are essential transcription factors required for the induction of the cytotoxic effector program in $\mathrm{CD}^{+} \mathrm{T}$ cells ${ }^{17,18}$. In contrast, the expression of CD4 lineage genes, such as $C d 4$ and $Z b t b 7 b$ (encoding for Th-POK) was reduced in HDAC1-2 cKO CD $4^{+} \mathrm{CD} 8{ }^{+} \mathrm{T}$ cells (0.4-fold and 0.5 -fold, respectively) (Supplementary Fig. 4c). Thus, certain genes characteristic for the CD8 lineage and for a CD8 effector program are de-repressed in CD4 lineage T cells in the absence of HDAC1 and HDAC2. 
Next, we tested whether the increased CD8 lineage gene expression in HDAC1-2 cKO CD4 lineage $\mathrm{T}$ cells correlated with the acquisition of CD8 effector functions upon activation. Because we observed a strong induction of apoptosis after 3 days of activation (Fig. 4g) during the culture of HDAC1-2 $\mathrm{cKO} \mathrm{CD} 4^{+} \mathrm{T}$ cells, similar to observations reported for $\mathrm{B}$ cells, fibroblasts and keratinocytes $7,9,10$, naïve HDAC1-2 cKO CD4 ${ }^{+} \mathrm{CD} 4^{+} \mathrm{T}$ cells and $\mathrm{CD}^{+} \mathrm{T}$ cells were activated with anti-CD3 and anti-CD28 only for 60 hours. Under these non-polarizing " $\mathrm{T}_{\mathrm{H}} 0$ " conditions, HDAC1-2 $\mathrm{cKO} \mathrm{CD} 4{ }^{+} \mathrm{T}$ cells produced increased amounts of IFN- $\gamma$ (Fig. 5a,c) and displayed increased expression of Granzyme B (approx. 7-fold on mRNA level) in comparison to activated WT CD4 ${ }^{+}$T cells (Fig. 5b,d). Moreover, Prf1 (encoding Perforin) expression was 4-fold higher (although not statistically significant) (Fig. 5b). In addition, HDAC1-2 cKO CD4 ${ }^{+} \mathrm{T}$ cells up-regulated Eomesodermin (approx. 23-fold on mRNA level) to a level equivalent to that in $\mathrm{CD} 8^{+} \mathrm{T}$ cells (Fig. 5b,c) and expressed significantly higher amounts of T-bet (encoded by $T b x 21$ ) (approx. 2.6-fold on mRNA level) (Fig. 5b,c) and Runx3 (approx. 2.5-fold) (Fig. 5b), while Zbtb7b expression was decreased (approx. 2-fold) (Fig. 5b). As observed for ex vivo activated HDAC1-2 cKO CD4 ${ }^{+} \mathrm{T}$ cells (Fig. 4c), sorted naïve HDAC1-2 $\mathrm{cKO} \mathrm{CD} 4{ }^{+} \mathrm{T}$ cells also up-regulated CD8 upon activation (Fig. 5d). Those HDAC1-2 cKO CD4 ${ }^{+} \mathrm{T}$ cells that up-regulated CD8a showed a similar cell division rate compared to the cells that were still CD8a-negative (Fig. 5e), making it unlikely that the appearance of HDAC1- $2 \mathrm{cKO} \mathrm{CD} 4^{+} \mathrm{CD} 8^{+} \mathrm{T}$ cells upon activation is due to a preferential expansion of cells that had already up-regulated CD8. Moreover, the expression of $C d 8 a$, Runx 3 and Eomes in activated HDAC1-2 cKO CD $4^{+} \mathrm{T}$ cells correlated with enhanced H3K9Ac histone marks at the promoter regions of these gene loci and at $C d 8$ enhancer $\mathrm{E} 8 \mathrm{I}$ in comparison to activated WT CD4 ${ }^{+} \mathrm{T}$ cells (Fig. 5f), while repressive H3K27me3 marks were reduced (Fig. 5f). We also examined the recruitment of HDAC1 and HDAC2 to the $C d 8 a, C d 8 b 1$, Runx 3 and Eomes promoter regions, and to E8, using ChiPassays. We observed HDAC1 and HDAC2 binding to the regulatory regions of CD8 lineage genes both in $\mathrm{CD}^{+}$and $\mathrm{CD} 8{ }^{+} \mathrm{T}$ cells (Supplementary Fig. 5a). Upon activation HDAC1 association with $\mathrm{CD} 8$ lineage genes was slightly increased in $\mathrm{CD} 4^{+} \mathrm{T}$ cells but was reduced in activated $\mathrm{CD} 8^{+} \mathrm{T}$ cells. In contrast, $\mathrm{HDAC} 2$ association with regulatory regions of $\mathrm{CD} 8$ lineage genes was increased upon activation both in $\mathrm{CD}^{+}$and $\mathrm{CD} 8^{+} \mathrm{T}$ cells (Supplementary Fig. 5a). This suggests that binding of HDAC1 and HDAC2 is not indicative whether the analyzed genes are repressed by HDAC1 and HDAC2 or not.

To further investigate the role of HDAC1 and HDAC2 in the repression of a CD8 lineage effector program, WT and HDAC1-2 cKO CD4 ${ }^{+} \mathrm{T}$ cells were polarized under $\mathrm{T}_{\mathrm{H}} 1$ and $\mathrm{T}_{\mathrm{H}} 2$ conditions. $\mathrm{T}_{\mathrm{H}} 1$-polarized HDAC1- $2 \mathrm{cKO} \mathrm{CD} 4^{+} \mathrm{T}$ cells displayed a similar up-regulation of CD8 lineage features as observed for HDAC1-2 cKO CD4 ${ }^{+} \mathrm{T}$ cells activated under $\mathrm{T}_{\mathrm{H}} 0$ conditions (Fig. 6a,b). In contrast, $\mathrm{T}_{\mathrm{H}} 2$ polarizing conditions repressed the induction of a CD8 program in the absence of HDAC1 and HDAC2 (Fig. 6a,b). Of note, the addition of IL-4 alone (in the absence of anti-IFN- $\gamma$ or anti-IL-12 blocking antibodies) was sufficient to repress the induction of CD8 in activated HDAC1-2 cKO CD4 ${ }^{+} \mathrm{T}$ cells (Fig. 6c). In contrast, the addition of IL-12 or IFN- $\gamma$ did not alter the degree of CD8 up-regulation upon activation (Fig. 6c) Together, these data indicate that HDAC1-HDAC2 are required for the repression of a CD8 lineage program in $\mathrm{T}_{\mathrm{H}} 0$ and $\mathrm{T}_{\mathrm{H}} 1$ cells, while HDAC1-2 $\mathrm{cKO} \mathrm{T}_{\mathrm{H}} 2$ polarized cells maintain the repression of a $\mathrm{CD} 8$ program. 


\section{Normal Th-POK expression in HDAC1-2 cKO CD4 ${ }^{+} \mathrm{T}$ cells}

The transcriptional regulator Th-POK (encoded by the Zbtb7b gene) has been implicated in the repression of the $C d 8$ loci and other CD8 lineage genes in CD4 lineage T cells ${ }^{19-22}$. Zbtb7b mRNA levels were reduced by $40-50 \%$ in HDAC1-2 cKO CD $4^{+} \mathrm{CD} 8^{+} \mathrm{T}$ cells compared to HDAC1-2 cKO CD4 $4^{+} \mathrm{T}$ cells and WT CD4 $4^{+} \mathrm{T}$ cells (Supplementary Fig. $4 \mathrm{c}, \mathrm{d}$ ). Immunoblot analysis indicated that Th-POK expression in $\mathrm{CD} 4^{+}$and $\mathrm{CD} 4^{+} \mathrm{CD} 8^{+} \mathrm{T}$ cells from HDAC1-2 cKO mice is similar to that in WT CD4 ${ }^{+}$T cells (Fig. 7a,b). Normal ThPOK protein amounts in $\mathrm{CD} 4^{+} \mathrm{CD} 8^{+} \mathrm{T}$ cells, despite reduced mRNA expression under homeostatic conditions, might indicate increased Th-POK protein stability in the absence of HDAC1 and HDAC2. To study Zbtb7b expression in single cells, we crossed HDAC1-2 cKO mice with Th-POK-GFP reporter knock-in mice, in which GFP expression is driven by the endogenous $Z b t b 7 b$ regulatory elements ${ }^{23}$. We found similar GFP expression in $\mathrm{CD}^{+}{ }^{+} \mathrm{T}$ cells from $Z b t b 7 b^{+/ G F P} \mathrm{WT}$ and $Z b t b 7 b^{+/ G F P} \mathrm{HDAC1}-2 \mathrm{cKO}$ mice, although the percentage of $\mathrm{GFP}^{+}$Th-POK-expressing CD4 ${ }^{+} \mathrm{T}$ cells was slightly reduced in HDAC1-2 cKO mice (Fig. 7c). Of note, a fraction (up to $25 \%$ ) of HDAC1-2 cKO CD8 ${ }^{+} \mathrm{T}$ cells expressed GFP (Fig. 7c). There was also high expression of GFP in $\mathrm{CD}^{+}{ }^{+} \mathrm{CD}^{+}{ }^{+} \mathrm{HDAC} 1-2 \mathrm{cKO} \mathrm{T}$ cells (Fig. 7c). Thus, CD8 lineage genes are de-repressed in HDAC1-2 cKO helper T cells under homeostatic conditions despite normal Th-POK protein expression.

\section{The CD8 effector program depends on Runx-CBF $\beta$}

Runx-CBF $\beta$ complexes are essential for the differentiation of CD8 effector T cells 17, 18, 24 . Runx3 protein was highly up-regulated (approx. 6-7 fold) in activated HDAC1-2 cKO CD4 ${ }^{+}$ $\mathrm{T}$ cells in comparison to WT CD4 ${ }^{+} \mathrm{T}$ cells (Fig. 8a). Runx 3 expression was also induced in activated wild-type $\mathrm{CD} 4^{+} \mathrm{T}$ cells in the presence of MS-275, a specific inhibitor of most class I HDACs (i.e. HDAC1, HDAC2 and HDAC 3$)^{25}$. To test whether the induction of CD8 lineage genes in HDAC1-2 cKO CD4 ${ }^{+} \mathrm{T}$ cells is dependent on Runx factors, HDAC1-2 cKO mice were crossed with $\mathrm{Cbfb}^{\mathrm{f} / \mathrm{f}}$ mice ${ }^{26}$ to induce conditional deletion of $\mathrm{CBF} \beta$. Activated CBF $\beta$-HDAC1-2 cKO CD4 ${ }^{+} \mathrm{T}$ cells displayed a marked reduction of CD8 effector program induction compared to HDAC1-2 $\mathrm{cKO} \mathrm{CD}^{+} \mathrm{T}$ cells, indicated by the diminished expression of CD8a, Eomesodermin, Granzyme B, T-bet and IFN- $\gamma$ (Fig. 8b,8c). Runx-CBF $\beta$ complexes bind to CD8 lineage genes such as Prfl, Gzbm, Infg ${ }^{18}$ and to $C d 8$ enhancer $\mathrm{E} 8_{\mathrm{I}}{ }^{16,27}$ in activated $\mathrm{CD} 8^{+} \mathrm{T}$ cells. Runx-CBF $\beta$ complexes bound to these gene regions in activated HDAC1-2 cKO CD4 $4^{+} \mathrm{T}$ cells, but not in wild-type $\mathrm{CD} 4^{+} \mathrm{T}$ cells (Fig. $8 d)$, suggesting that Runx-CBF $\beta$ complexes are required for the induction of CD8 lineage genes in HDAC1-2 cKO helper T cells.

Next, Runx3 was retrovirally expressed in wild-type $\mathrm{CD} 4^{+} \mathrm{T}$ cells in the presence or absence of MS-275. MS-275 treatment of $\mathrm{CD}^{+} \mathrm{T}$ cells transduced with MIGR-control vector induced the expression of CD8a, Eomesodermin, IFN- $\gamma$ and T-bet (Fig. 8e), indicating that class I HDACs are required to maintain the repression of these CD8 effector genes, in addition to Runx3 (Fig. 8a), in CD4 lineage T cells. Of note, MS-275 treatment of activated $\mathrm{CD} 8^{+} \mathrm{T}$ cells did not up-regulate $\mathrm{CD} 4$ expression (data not shown). Enforced expression of Runx3 induced CD8a, Granzyme B and IFN- $\gamma$ expression (Fig. 8e), which were further up-regulated in synergy with MS-275 (Fig. 8e). In contrast, treatment of Runx3-transduced cells with the HAT inhibitor anacardic acid ${ }^{28}$ reduced the effect of 
Runx3 on the induction of CD8 but not on Granzyme B or IFN- $\gamma$ expression (Fig. 8e). Similarly, anacardic acid treatment antagonized the up-regulation of CD8 in HDAC1-2 cKO $\mathrm{CD}^{+}{ }^{+} \mathrm{T}$ cells (Fig. 8f). Finally, MS-275-treated E8 $\mathrm{I}^{-/-}$or $\mathrm{Cbfb} b_{-}^{\mathrm{f} / \mathrm{f}} \mathrm{Cd} 4-\mathrm{Cre} \mathrm{CD} 4^{+} \mathrm{T}$ cells displayed impaired up-regulation of CD8 (Fig. 8g) and the up-regulation of CD8 upon enforced expression of Runx3 and MS275 treatment was reduced in $\mathrm{E}_{\mathrm{I}}^{-{ }^{--}} \mathrm{CD} 4^{+} \mathrm{T}$ cells in comparison to wild-type $\mathrm{CD} 4^{+} \mathrm{T}$ cells (data not shown), suggesting an important role for $\mathrm{E} 8$ I and Runx-CBF $\beta$ in the induction of CD8 expression.

The CD8 effector program was not induced in HDAC1-2 cKO CD4 ${ }^{+} \mathrm{T}$ cells under $\mathrm{T}_{\mathrm{H}} 2$ polarizing conditions (Fig. 6a,b). GATA-3, which is a key factor driving $\mathrm{T}_{\mathrm{H}} 2$ differentiation, inhibits $\mathrm{T}_{\mathrm{H}} 1$ differentiation and was shown to repress Runx3-mediated Ifng induction $29,30$. To test whether GATA-3 might counteract the MS-275-mediated induction of CD8, we retrovirally expressed GATA- 3 in wild-type $\mathrm{CD}^{+}{ }^{+} \mathrm{T}$ cells in the presence or absence of MS-275. While MIGR-control vector transduced cells up-regulated CD8 expression upon MS-275 treatment, GATA-3 expressing cells showed a reduced up-regulation of CD8 (Supplementary Fig. 5b). This indicates that GATA-3 impairs the up-regulation of CD8 upon inhibition of class I HDACs.

Together, these data suggest that the induction of a CD8 effector program in the absence of HDAC 1 and HDAC 2 is dependent on the activity of Runx-CBF $\beta$ complexes and that class I HDACs are required to maintain the repression of a CD8 effector program in CD4 lineage $\mathrm{T}$ cells.

\section{Loss of HDAC1-HDAC2 affects potential non-histone targets}

HATs and HDACs mediate dynamic changes in the acetylation of core histones at lysine residues and are thus considered key epigenetic regulators of gene expression. Many nonhistone targets of HATs/HDACs, however, are emerging in which lysine acetylation has been shown to affect protein-protein and protein-DNA interactions, protein stability and intracellular localization ${ }^{31}$. To identify potential non-histone HDAC targets that might have an altered stability due to the lack of HDAC1-HDAC2, we investigated whether there are differences in protein expression levels but not in mRNA expression level. Therefore, we performed a mass spectrometry analysis of WT and HDAC1-2 cKO CD $4^{+} \mathrm{T}$ cells under homeostatic conditions. This revealed 255 proteins as differentially abundant in the absence of HDAC1-HDAC2 (out of 5138 quantitated proteins) (Supplementary Table 2). A correlative analysis of the proteomic data and the gene expression arrays identified 189 genes as differentially expressed at the protein but not at the mRNA level (Supplementary Fig. 5c and Supplementary Table 3). This indicates potential non-histone targets of HDAC1HDAC2 that might have altered protein stability due to changes in post-translational lysine acetylation patterns. Thus, loss of HDAC1-HDAC2 affects $\mathrm{CD} 4{ }^{+} \mathrm{T}$ cells at the transcriptional (chromatin) and posttranslational level.

\section{Discussion}

In this study we provide genetic evidence that $\mathrm{HDAC} 1$ and $\mathrm{HDAC} 2$ control $\mathrm{CD} 4^{+} \mathrm{T}$ cell lineage integrity and $\mathrm{T}$ cell homeostasis. $\mathrm{CD} 4^{+}$and $\mathrm{CD} 4^{+} \mathrm{CD} 8^{+} \mathrm{T}$ cells in HDAC1-2 cKO mice were MHC class II-restricted, expressed Th-POK under homeostatic conditions and 
up-regulated CD154 upon activation, thus displaying defined features of CD4 lineage cells. However, the observation that a Runx-CBF $\beta$ complexes-dependent CD8 effector program is up-regulated in HDAC1-2 cKO CD4 lineage cells upon activation revealed that HDAC1$\mathrm{HDAC} 2$ are essential to repress CD8 lineage features in $\mathrm{CD} 4^{+} \mathrm{T}$ cells. Moreover, our study showed that late ( $C d 4$-Cre) deletion of HDAC1 and HDAC2 leads to reduced numbers of peripheral $\mathrm{T}$ cells and to a strong induction of apoptosis in $\mathrm{CD} 4^{+} \mathrm{T}$ cells after 3 days of activation. This indicates that HDAC1 and HDAC 2 are also essential for the generation of the peripheral $\mathrm{T}$ cell pool and for the survival of proliferating $\mathrm{CD} 4^{+} \mathrm{T}$ cells. .

Our data show that HDAC1 and HDAC2 repress $\mathrm{CD} 8$ lineage features in $\mathrm{CD} 4^{+} \mathrm{T}$ cells. The presence of a small fraction of HDAC1-2 $\mathrm{cKO} \mathrm{CD} 4^{-} \mathrm{CD} 8^{+} \mathrm{T}$ cells in MHC class I-chimeric mice might suggest that some MHC class II-restricted HDAC1-2 $\mathrm{cKO} \mathrm{CD} 4^{+} \mathrm{T}$ cells were redirected into the CD8 lineage. Runx-CBF $\beta \chi 0 \mu \pi \lambda \varepsilon \xi \varepsilon \sigma$ are essential for the differentiation of CD8 effector T cells 17, 18, 24. Based on our data we propose that HDAC1 and HDAC2 maintain CD4 lineage integrity by repressing Runx-CBF $\beta$ complexes. Our mRNA expression analysis and ChIP experiments suggested that HDAC1 and HDAC2 directly suppress the transcription of the Runx 3 gene in $\mathrm{CD} 4^{+} \mathrm{T}$ cells. It is conceivable that the strong induction of Runx 3 expression in HDAC1-2 cKO CD4 lineage T cells is the initiating event in the induction of a CD8 effector program, in part via recruitment of Runx-CBF $\beta$ complexes to target genes such as $C d 8, G z m B, P r f l$ and Ifng. Within the $C d 8 a b$ gene complex, Runx-CBF $\beta$ complexes were bound to the $C d 8$ enhancer $\mathrm{E}_{\mathrm{I}}$ and the induction of CD8 in HDAC1-2 cKO CD4 ${ }^{+} \mathrm{T}$ cells was largely dependent on E8. Preliminary data using $C d 8$ enhancer $\mathrm{E} 8_{\mathrm{I}}, \mathrm{E} 8_{\mathrm{II}}$-deficient mice ${ }^{32}$ also indicate a role for $\mathrm{E} 8_{\mathrm{II}}$ in this process, because HDAC1-2 cKO CD4 ${ }^{+} \mathrm{T}$ cells did not up-regulate CD8 under homeostatic conditions in the combined absence of E8 $8_{\text {I }}$ and E $8_{\text {II }}$ (data not shown). Moreover, Eomesodermin and T-bet, which are important for the induction of the cytotoxic program ${ }^{17}$, were up-regulated in HDAC1-2 cKO CD4 lineage T cells in a Runx-CBF $\beta$-dependent manner, and it is conceivable that Runx3, Eomesodermin and T-bet together regulate the induction of the CD8 effector program in HDAC1-2 $\mathrm{cKO} \mathrm{CD} 4^{+} \mathrm{T}$ cells. Th-POK, which is a master commitment factor for the development of CD4 lineage T cells ${ }^{33,34}$, represses the expression of CD8 lineage-specific genes ${ }^{20-22}$. Loss of HDAC1 and HDAC2 recapitulates in part the phenotype of a "hypomorphic" $Z b t b 7 b$ allele in $\mathrm{CD}^{+} \mathrm{T}$ cells, which acquire some CD8 characteristics and start to express certain cytotoxic effector genes such as Perforin and Granzyme B ${ }^{21,22}$. Ex vivo, HDAC1-2 cKO CD4 ${ }^{+} \mathrm{CD}^{+} \mathrm{T}$ cells had similar ThPOK protein expression as WT and HDAC1-2 $\mathrm{cKO} \mathrm{CD} 4^{+} \mathrm{T}$ cells, although Zbtb7b mRNA expression was slightly reduced in $\mathrm{HDAC} 1-2 \mathrm{cKO} \mathrm{CD} 4^{+} \mathrm{CD} 8^{+} \mathrm{T}$ cells in comparison to WT and HDAC1-2 $\mathrm{cKO} \mathrm{CD} 4^{+} \mathrm{T}$ cells. This might indicate that HDAC1 and HDAC2 are part of a regulatory complex that controls Th-POK stability, since acetylation of Th-POK, mediated by the HAT $\mathrm{p} 300$, has been shown to stabilize Th-POK protein ${ }^{35}$. Thus, the derepression of certain CD8 lineage genes in $\mathrm{CD} 4^{+} \mathrm{T}$ cells in the absence of HDAC1 and HDAC2 under homeostatic conditions is not due to reduced Th-POK protein expression, although we cannot rule out that Th-POK requires (in part) HDAC1 and HDAC2 to exert its activity. However, HDAC1-2 cKO CD4 ${ }^{+} \mathrm{T}$ cells upon activation down-regulated $Z b t b 7 b$ expression compared to activated wild-type $\mathrm{CD} 4^{+} \mathrm{T}$ cells, thus it is likely that reduced $\mathrm{Zbtb} b \mathrm{~b}$ 
expression might enhance and/or contribute to the induction of a CD8 effector program upon activation in the absence of HDAC1 and HDAC2.

The induction of a CD8 effector program was repressed in HDAC1-2 $\mathrm{cKO} \mathrm{CD} 4^{+} \mathrm{T}$ cells under $\mathrm{T}_{\mathrm{H}} 2$ polarizing conditions. This demonstrates that the up-regulation of $\mathrm{CD} 8$ effector genes is not a "general" feature of HDAC1-2 cKO CD4 $4^{+} \mathrm{T}$ cells. The key $\mathrm{T}_{\mathrm{H}} 2$ transcription factor GATA-3 inhibits $\mathrm{T}_{\mathrm{H}} 1$ differentiation and was shown to repress Runx3-mediated Ifng induction ${ }^{29,30}$. Our observation that enforced GATA-3 expression in MS-275-treated wildtype $\mathrm{CD} 4^{+} \mathrm{T}$ cells impaired the up-regulation of $\mathrm{CD} 8$ suggests that GATA-3 contributes to the repression of a CD8 program in $\mathrm{T}_{\mathrm{H}} 2$ cells in the absence of HDAC1 and HDAC2, perhaps via blocking the activity of Runx3. In contrast, CD8 up-regulation was not influenced by enforced expression of Eomesodermin (data not shown). Preliminary results indicate that HDAC1-2 $\mathrm{cKO} \mathrm{T}_{\mathrm{H}} 17$ cells also repress the induction of a CD8 effector program (data not shown), suggesting that other factors in addition to GATA-3 might be able to interfere with the activity of Runx 3 in the absence of HDAC1 and HDAC2 as well. Further studies are required to investigate the regulatory hierarchy among HDAC1-HDAC2, Runx3, Th-POK, Eomesodermin, T-bet and GATA-3.

Our study also provides new insight into HDAC1 and HDAC2-mediated transcriptional regulation of the $\mathrm{T}$ cell transcriptome. The expression of a surprisingly low number of genes was altered in HDAC1-2 cKO CD4 ${ }^{+} \mathrm{T}$ cells (612 genes, $>2$-fold absolute change; $\mathrm{P}<0.05$ ), indicating a high specificity of $\mathrm{HDAC} 1$ and HDAC2 in the regulation of gene expression. More genes were up- than down-regulated in HDAC1-2 $\mathrm{cKO} \mathrm{CD}^{+} \mathrm{T}$ cells, demonstrating the repressive function of HDAC1-HDAC2 containing complexes. Future experiments employing ChIP-seq approaches will be important to determine which of the deregulated genes are direct HDAC1-HDAC2 target genes, although our ChIP assays on selected CD8 lineage genes suggest that HDAC1 and HDAC2 binding is not indicative whether a gene is repressed by HDAC1-HDAC2 or not.

HDACs are considered as general chromatin-modifying regulators of gene expression, although many non-histone targets of HATs and HDACs are current emerging. Lysine acetylation of proteins has been shown to affect protein-protein and protein-DNA interactions, protein stability and intracellular localization and many non-histone targets of HATs/HDACs are emerging ${ }^{31}$. The correlative analysis of our proteomic data with gene expression arrays identified 189 genes as differentially expressed between WT and HDAC1- 2 cKO CD4 ${ }^{+} \mathrm{T}$ cells at the protein but not at the mRNA level. This indicates potential non-histone targets of HDAC1 and HDAC2 that might have altered protein stability due to changes in posttranslational lysine acetylation patterns. Thus, these data suggests that loss of $\mathrm{HDAC} 1$ and $\mathrm{HDAC} 2$ affects $\mathrm{CD} 4^{+} \mathrm{T}$ cells at the transcriptional (chromatin) as well as posttranslational modification level. Runx3 protein amounts can be controlled by competitive lysine acetylation and deacetylation ${ }^{36}$, suggesting an additional post-translational regulation of Runx3 expression, although preliminary data using cycloheximide approaches suggest that Runx3 stability is not increased in activated HDAC1-HDAC2-deficient $\mathrm{CD}^{+} \mathrm{T}$ cells (data not shown). Further studies are required to determine whether posttranslational modifications of Runx3 are altered in the absence of HDAC1 and HDAC2 that affect Runx3 activity and/or stability. 
Finally, our study also shows that HDAC2 is not required for (late) T cell development and the generation of the peripheral T cell pool. Since HDAC1- and HDAC2-deficient T cells displayed a compensatory up-regulation of HDAC2 and HDAC1, respectively, it is likely that a combined activity of either HDAC 1 and HDAC 2 above a certain threshold is sufficient to allow proper T cell development. Loss of HDAC1 and HDAC2 in murine embryonic fibroblasts ${ }^{9}$, keratinocytes ${ }^{7}$ or B cells ${ }^{10}$ leads to a cell cycle block at the G1 to $\mathrm{S}$ transition and an induction of apoptosis. Similarly, loss of HDAC1 and HDAC2 at early stages of $\mathrm{T}$ cell development ( $L c k$-Cre) leads to a severe reduction of thymocyte numbers, most likely due to a block in the cell cycle progression at the pre-TCR stage ${ }^{11,12}$. A potential explanation why peripheral $\mathrm{T}$ cells are still present, although at reduced numbers, upon simultaneous ablation of HDAC1 and HDAC2 using $\mathrm{Cd} 4 \mathrm{Cre}$ might be the low proliferation rate of mature SP thymocytes and naive peripheral T cells, allowing those cells to keep the amount of residual HDAC1 and HDAC2 protein upon deletion of the Hdacl and $H d a c 2$ alleles at levels sufficient for survival. However, the increase in Annexin $\mathrm{V}^{+} \mathrm{T}$ cells under homeostatic conditions and the strong induction of apoptosis in $\mathrm{CD}^{+} \mathrm{T}$ cells after 3 days of activation indicates that HDAC1 and HDAC2 are also essential for the generation of the peripheral $\mathrm{T}$ cell pool and for the survival of proliferating $\mathrm{CD} 4^{+} \mathrm{T}$ cells.

In summary, our study provides genetic evidence that HDAC1 and HDAC2 repress a Runx/ $\mathrm{CBF} \beta$-dependent $\mathrm{CD} 8$ effector program in $\mathrm{CD}^{+} \mathrm{T}$ cells and thus control the integrity of CD4 lineage T cells.

\section{ONLINE METHODS}

\section{Animal models}

All animal experiments were evaluated by the ethics committees of the Medical University of Vienna and approved by the Federal Ministry for Science and Research, Vienna, Austria (GZ:BMWF-66.009/0057-II/10b/2010 and GZ:BMWF-66.009/58-II/10b/2010). Animal husbandry and experimentation was performed under the national laws (Federal Ministry for Science and Research, Vienna, Austria) and ethics committees of the Medical University of Vienna and according to the guidelines of FELASA which match that of ARRIVE.

Mice carrying floxed $\mathrm{Hdacl}$ and $\mathrm{Hdac2}$ alleles have been described ${ }^{10}$. Cd4-Cre mice were kindly provided by Dr. Chris Wilson. MHC class II-deficient $\left(H 2-A b 1^{-/}\right)$and MHC class Ideficient $\left(B 2 \mathrm{~m}^{-/-}\right)$mice were obtained from Taconic. OT-II TCR transgenic mice were kindly provided by Dr. Stoiber-Sakaguchi (Medical University of Vienna). E8 ${ }^{-/-}$, E8 ${ }_{\text {I }}^{-/-}{ }^{-} 8_{\text {II }^{-1-}}{ }^{-1}, Z b t b 7 b$-GFP knock-in, Runx $3^{\mathrm{f} / \mathrm{f}}$ and $C b f b^{\mathrm{f} / \mathrm{f}}$ mice have been described $23,26,32,37$. All mice analyzed were 8-12 weeks of age and of mixed sex unless otherwise stated. Littermate controls were used for FACS stainings within one experiment.

\section{Generation of bone marrow chimeric mice}

BM transplantation was done as described ${ }^{16}$. Six to eight weeks after transplantation, the reconstituted mice were sacrificed and analyzed by flow cytometry (LSRII; BD Biosciences). 


\section{Flow cytometry analysis and antibodies}

Antibodies used in this study are listed in Supplementary Table 4.

\section{Isolation and activation of $\mathbf{T}$ cells}

$\mathrm{CD} 4^{+}$and $\mathrm{CD} 8^{+} \mathrm{T}$ cells were isolated from 6 weeks old mice as previously described ${ }^{6}$. Cells $\left(1 \times 10^{6}\right.$ cells in $\left.1 \mathrm{ml}\right)$ were seeded onto 48 well cell culture plates coated with anti$\mathrm{CD} 3 \varepsilon(1 \mu \mathrm{g} / \mathrm{ml})$ and anti-CD28 (3 $\mu \mathrm{g} / \mathrm{ml})$ (BD Pharmingen). Cells were then harvested at various time points dependent on the experimental setting for flow cytometric analysis as indicated in the Figure legends. For cell proliferation experiments, purified $\mathrm{CD} 4^{+} \mathrm{T}$ cells were labeled with CFSE (Molecular Probes, Eugene, OR) or v450 proliferation dye (eBioscience) before activation as previously described ${ }^{6}$.

\section{Differentiation of $\mathrm{CD4}^{+} \mathrm{T}$ cells and cytokine measurements}

Sorted naive $\left(\mathrm{CD} 44^{\text {low }}{ }^{\mathrm{CD}} 62 \mathrm{~L}^{+}\right) \mathrm{CD} 4^{+} \mathrm{T}$ cells were stimulated (day 0 ) with plate-bound anti-CD3 $\varepsilon(1 \mu \mathrm{g} / \mathrm{ml})$ and anti-CD28 $(3 \mu \mathrm{g} / \mathrm{ml})$ on 96-well plates $\left(2 \times 10^{5}\right.$ cells/well $)$ in 200 $\mu \mathrm{T}$ cell medium (RPMI GlutaMAX-I supplemented with 10\% FCS, antibiotics, and 2-ME; all from Invitrogen) under various cytokine conditions. For $\mathrm{T}_{\mathrm{H}} 0$ conditions (non-polarizing) recombinant human IL-2 (hIL-2) $(20 \mathrm{U} / \mathrm{ml})$ was added; for $\mathrm{T}_{\mathrm{H}} 1$ conditions, rhIL-2 (20 U/ $\mathrm{ml})$, IL-12 (5 ng/ml), and anti-IL-4 (3 $\mu \mathrm{g} / \mathrm{ml})$; for $\mathrm{T}_{\mathrm{H}} 2$ conditions, rhIL-2 (10 U/ml), IL-4 $(250 \mathrm{U} / \mathrm{ml})$, anti-IFN- $\gamma(10 \mu \mathrm{g} / \mathrm{ml})$, and anti-IL-12 $(10 \mu \mathrm{g} / \mathrm{ml})$. Cells were analyzed after 60 hours.

\section{Intracellular cytokine, transcription factor and Granzyme B stainings}

$\mathrm{T}$ cells were cultured under various conditions as described above. For intracellular cytokine detection, cells were stimulated in 96-well plates at $10^{6}$ cells $/ \mathrm{ml}$ for $4 \mathrm{~h}$ with PMA (50 $\mathrm{ng} / \mathrm{ml}$ ) and ionomycin $(500 \mathrm{ng} / \mathrm{ml}$ ) (Sigma-Aldrich) in the presence of GolgiStop (BD Biosciences). After harvesting, $T$ cells were surface stained with appropriate antibodies. Subsequently, cells were fixed with cytofix Fixation Buffer (BD Biosciences), permeabilized with Perm/Wash Buffer (BD Biosciences), and stained for intracellular proteins according to the manufacturer's protocol.

\section{BrdU incorporation experiments}

Mice were injected intraperitoneally with $1 \mathrm{mg}$ (in $200 \mu \mathrm{l}$ ) BrdU. 4 days later, thymocytes were isolated, stained for surface markers. Subsequently, BrdU was detected with the Apoptosis, DNA Damage and Cell Proliferation Kit (BD Biosciences) according to the manufacturer's protocol.

\section{Apoptosis detection assay}

Apoptosis of ex vivo analyzed and of cultured T cells was detected by Annexin V and 7AAD stainings following the Annexin V Apoptosis detection kit (eBioscience), according to the manufacturer's instructions. 


\section{Intracellular HDAC1 and HDAC2 staining}

Splenocytes were pre-incubated with Fc-block (BD Pharmingen) and stained with antiCD8a, CD4 and TCR $\beta$ antibodies. For immunodetection of HDAC1 and HDAC2, cells were fixed and permeabilized using Foxp3 Fixation/Permeabilization Concentrate and Diluent (eBioscience) according to the manufacturer's instruction. Subsequently, cells were blocked in 5\% normal goat serum and then incubated with rabbit anti-mouse HDAC1 and mouse anti-mouse HDAC2 antibodies in permeabilization buffer (eBioscience) for 1 hour. Cells were washed with permeabilization buffer and incubated with Alexa Fluor ${ }^{\circledR} 488$-conjugated goat anti-rabbit IgG1 and biotinylated anti-mouse IgG1 antibodies, followed by a Streptavidin secondary staining.

\section{cDNA synthesis and quantitative real-time PCR}

Cells were harvested with TRIZOL reagent (Invitrogen), and total RNA was isolated according the manufacturer's instructions. RNA was reversely transcribed using the iScript cDNA synthesis kit (Bio-Rad). Quantitative real-time PCR (qRTPCR) analysis was performed with the SuperScript III qPCR MasterMix (Invitrogen) on the CFX 96 Real-Time PCR detection system (Bio-Rad).

\section{Chromatin immunoprecipitation assays}

Preparation of soluble chromatin was carried out as previously described ${ }^{6}$. For HDAC1 and HDAC2 ChIPs the T cells were pre-treated with the crosslinker disuccinimidyl glutarate (2mM mM, AppliChem) for $25 \mathrm{~min}$ at room temperature. Chromatin was sonicated with the Bioruptor ${ }^{\circledR}$ Sonication System (Diagenode). For ChIP assays equal amounts of sonicated chromatin were diluted 10-fold and precipitated overnight with the following antibodies: rabbit anti-mouse HDAC1 (affinity purified polyclonal serum ${ }^{38}$ ), mouse anti-mouse HDAC2 (Abcam ab12169), anti-H3K9ac (Millipore 07-449), C-terminal H3 (Abcam ab1791), rabbit IgG (Invitrogen), mouse IgM (Invitrogen) and CBF $\beta^{26}$ as a control. Chromatin/antibody complexes were isolated using Protein A or Protein G magnetic beads (Dynabeads, Invitrogen). The extracted DNA was used for qRTPCR analysis with an iCycler IQ system (Bio-Rad) and KAPA SYBR FAST qPCR MasterMix (Peqlab). In parallel, PCR reactions with 1:20 dilutions of genomic DNA (input) were carried out. Values for histone $\mathrm{H} 3$ modification marks were corrected to the $\mathrm{H} 3$ values obtained with $\mathrm{C}$ terminal $\mathrm{H} 3$ antibody.

\section{Primers}

Primers used in this study are listed in Supplementary Table 5.

\section{HDAC and HAT inhibitor experiments}

$\mathrm{CD}^{+}$or $\mathrm{CD}^{+} \mathrm{T}$ cells were isolated from lymph nodes and spleens of C57BL/6, $\mathrm{E}_{I^{-1-}}$ or $\mathrm{Cbfb}^{\mathrm{f} / \mathrm{f}} \mathrm{Cd}$-Cre mice and activated as described above. After activation for $24 \mathrm{~h}$, either MS-275 (Selleck Chemicals, used at a final concentration of $2 \mu \mathrm{M}$ with DMSO as a carrier control) or anacardic acid (Sigma Aldrich, used at a final concentration of $20 \mu \mathrm{M}$ with $\mathrm{EtOH}$ as a carrier control) was added and cells were cultured for additional 24h. Afterwards, cells 
were stained as described and analyzed on a FACScalibur or LSRII flow cytometer (BD Biosciences).

\section{Retroviral expression of Runx3 and GATA3}

The cDNA encoding for the distal-promoter-derived Runx $3 d$ protein was cloned into the MIGR retroviral vector. GATA3 vector was kindly provided by Dr. Jianfang Zhu. High-titer viral preparations were generated as described ${ }^{16}$. Wild-type $\mathrm{C} 57 \mathrm{BL} / 6 \mathrm{CD} 4^{+} \mathrm{T}$ cells $(0.5 \times$ $10^{6}$ cells in $1 \mathrm{ml}$ ) were activated in 48 well tissue-culture plates coated with anti-CD3 $\varepsilon$ $(0.5 \mu \mathrm{g} / \mathrm{ml})$ and anti-CD28 $(1 \mu \mathrm{g} / \mathrm{ml})$ in the presence of $10 \mathrm{U} / \mathrm{ml} \mathrm{rhIL-2}$. After $24 \mathrm{~h}$, the culture medium was aspirated and $1 \mathrm{ml}$ virus-containing supernatant was added per well. Spin infection was performed by centrifugation of the plates at $600 \times \mathrm{g}$ for $1 \mathrm{~h}$ at $32^{\circ} \mathrm{C}$. The supernatant was removed and fresh medium containing $10 \mathrm{U} / \mathrm{ml} \mathrm{rhIL-2} \mathrm{was} \mathrm{added.} \mathrm{Twenty-}$ four hours later, MS-275 $(2 \mu \mathrm{M}$, with DMSO as carrier control) or anacardic acid $(20 \mu \mathrm{M}$, with $\mathrm{EtOH}$ used as carrier control) was added to a final concentration of $2 \mu \mathrm{M}$. Cells were cultured for additional $24 \mathrm{~h}$, stained as indicated in the figure legends and analyzed on a LSRII flow cytometer.

\section{Immunoblot analysis}

T cells $\left(0.6 \times 10^{6}\right)$ were lysed in $(35 \mu \mathrm{l})$ Carin lysis buffer $(20 \mathrm{mM}$ Tris- $\mathrm{HCl}$ [pH 8.0], 138 $\mathrm{mM} \mathrm{NaCl}, 10 \mathrm{mM}$ EDTA, $100 \mathrm{mM} \mathrm{NaF}, 1 \%$ Nonidet P-40, 10\% glycerol, $2 \mathrm{mM} \mathrm{Na}$ vanadate) supplemented with complete protease inhibitors (Roche). Proteins were separated on 10\% SDS-polyacrylamide gels and blotted onto PVDF membranes according to standard protocols. The following primary antibodies were used: anti-actin (AC-74; Sigma-Aldrich, St. Louis, MO), mouse anti-Runx3 (2B3; Abcam) and rabbit anti-Th-POK ${ }^{22}$. Secondary antibodies were a peroxidase-conjugated AffiniPure goat anti-rabbit $\operatorname{IgG}(\mathrm{H}+\mathrm{L})$ (Jackson ImmunoResearch Laboratories) and a HRP-conjugated AffiniPure Goat Anti-Mouse IgG (Jackson ImmunoResearch Laboratories). Signals were detected using ECL (SuperSignal West Dura Extended Duration Substrate from ThermoScientific).

\section{Quantitative Proteomic Analysis of CD4+ T-cells}

Quantitative proteomic analysis was performed on sorted splenic CD4+ T-cells. Sample downstream processing was adapted from the filter-aided sample preparation method (FASP) ${ }^{43,44}$. Briefly, two biological replicates, each containing $800,000 \mathrm{CD}^{+} \mathrm{T}$-cells, were lysed in $80 \mu \mathrm{L} 50 \mathrm{mM}$ HEPES buffer, $\mathrm{pH} 8.5$ supplemented with $2 \%$ sodium dodecyl sulphate (SDS). Samples were sonicated to shear the DNA and reduce viscosity. Proteins were reduced with $100 \mathrm{mM}$ dithiothreitol (DTT) and samples were transferred into VIVACON 500 filter units (Vivaproucts Inc., Littleton, MA). SDS-containing buffer was removed from the sample by centrifugation and exchanged with $8 \mathrm{M}$ urea in $100 \mathrm{mM}$ Tris$\mathrm{HCl}$ buffer. Proteins were alkylated with $50 \mathrm{mM}$ iodoacetamide and washed with $50 \mathrm{mM}$ triethylammonium bicarbonate (TEAB). Finally, porcine trypsin (Promega Corp., Madison, WI) was used for protein digestion in an enzyme to protein ratio of 1:100 w/w.

For relative quantitation, a set of four samples (two biological replicates each from the WT and HDAC1-2 cKO CD4 ${ }^{+} \mathrm{T}$ cells) were separately derivatised with 4-plex iTRAQ reagents (ABI, Framingham, MA) according to the instructions provided by the manufacturer. 
iTRAQ-labelled tryptic digests were pooled and concentrated by solid phase extraction (SPE) (MicroSpin columns 3-300 $\mu$ g capacity, The Nest Group Inc., Southborough, MA, USA). Samples were basified with $20 \mathrm{mM}$ ammonium fomate prior to injection onto a Phenomenex column $\left(150 \times 2.0 \mathrm{~mm}\right.$ Gemini ${ }^{\circledR} \mathrm{NX}-\mathrm{C} 183 \mu \mathrm{m} 110 \AA$; Phenomenex, Torrance, CA, USA) on an Agilent 1200 series HPLC (Agilent Biotechnologies, Palo Alto, CA) with UV detection at $214 \mathrm{~nm}$. HPLC solvent A consisted of $20 \mathrm{mM}$ ammonium formate, $\mathrm{pH} 10$ in $5 \%$ acetonitrile while solvent $\mathrm{B}$ contained of $20 \mathrm{mM}$ ammonium formate, $\mathrm{pH} 10$ in $90 \%$ acetonitrile. Peptides were separated at flow rate of $100 \mu \mathrm{L} / \mathrm{min}$ and eluted from the column with a non-linear gradient ranging from 0 to $100 \%$ solvent B. Seventy two time-based fractions were collected, acidified and pooled into 50 HPLC vials based on the UV trace. After removal of organic solvent in a vacuum centrifuge, samples were reconstituted to 10 $\mu \mathrm{L}$ with $5 \%$ formic acid ${ }^{45}$. Individual fractions were further analysed at $\mathrm{pH} 2.4$ by Agilent 1200 nano-HPLC system (Agilent Biotechnologies, Palo Alto, CA) coupled to a hybrid linear trap quadrupole (LTQ) Orbitrap Velos mass spectrometer (ThermoFisher Scientific, Waltham, MA) utilising Xcalibur software version 2.1. for data acquisition. Briefly, single fractions were loaded onto a trap column (Zorbax 300SB-C18 $5 \mu \mathrm{m}, 5 \times 0.3 \mathrm{~mm}$, Agilent Biotechnologies, Palo Alto, CA) with a binary pump at a flow rate of $45 \mu \mathrm{L} / \mathrm{min}$. Solvents for LCMS separation were composed of $0.1 \%$ trifluoracetic acid (TFA) in water (solvent A) and $0.1 \%$ TFA in $70 \%$ methanol and $20 \%$ isopropanol (solvent B). The peptides were eluted by back-flushing from the trap column onto a $16 \mathrm{~cm}$ fused silica analytical column with an inner diameter of $50 \mu \mathrm{m}$ packed with C18 reversed-phase material (ReproSil-Pur $120 \mathrm{C} 18$ $\mathrm{AQ}, 3 \mu \mathrm{m}$, Dr. Maisch GmbH, Ammerbuch-Entringen, Germany). Elution was achieved with a 27 min gradient ranging from 3 to $30 \%$ solvent $\mathrm{B}$, followed by a 25 min gradient from 30 to $70 \%$ solvent B and, finally, a 7 min gradient from 70 to $100 \%$ solvent B at a constant flow rate of $100 \mathrm{~nL} / \mathrm{min}$.

The analysis was performed in a data-dependent acquisition mode using 10 most intense peaks for high-energy collision-induced dissociation (HCD), subsequent peptide identification and relative quantitation of iTRAQ ${ }^{\circledR}$ reporter ions. Dynamic exclusion for selected ions was $60 \mathrm{~s}$ and a single lock mass at $\left.\left.m / z 445.120024\left(\mathrm{Si}_{(\mathrm{C}}\left(\mathrm{CH}_{3}\right)_{2} \mathrm{O}\right)_{6}\right) 2\right)$ was used for internal mass calibration with the target loss mass abundance of $0 \%$. Maximal ion accumulation time allowed was $500 \mathrm{~ms}$ and overfilling of the C-trap was prevented by automatic gain control set to $10^{6}$ ions for a full FTMS scan and $5 \times 10^{5}$ ions for MS ${ }^{\mathrm{n}} \mathrm{HCD}$. Intact peptides were detected in the Orbitrap mass analyser at resolution of 30,000 with the signal threshold of 2,000 counts for triggering an MSMS event. The maximum ion scan time was set to $200 \mathrm{~ms}$ for acquiring 1 microscan at a resolution of 7,500.

\section{Mass spectrometry data file processing}

The acquired raw MS data files were processed with msconvert (ProteoWizard Library v2.1.2708) and converted into Mascot generic format (mgf) files. Peptide identification was performed by searching the resultant peak lists against the SwissProt mouse database version v2013.01_20130110 (24615 sequences; 14280050 residues) with the search engines Mascot (v2.3.02, MatrixScience, London, UK) and Phenyx (v2.5.14, GeneBio, Geneva, Switzerland) ${ }^{46}$. Submission to the search engines was via a Perl script that performs an initial search with relatively broad mass tolerances (Mascot only) on both the precursor and 
fragment ions ( $\pm 10 \mathrm{ppm}$ and $\pm 0.6 \mathrm{Da}$, respectively). High-confidence peptide identifications were used to recalibrate all precursors and fragment ion masses prior to a second search with narrower mass tolerances ( $\pm 4 \mathrm{ppm}$ and $\pm 0.025 \mathrm{Da}$ ). Trypsin was chosen as cleavage specificity with the maximum of 1 miscleavage site allowed. Carbamidomethyl cysteine, Nterminal and lysine-modified iTRAQ 4-plex were set as fixed modifications, whereas oxidised methionine was set as a variable modification.

To validate the proteins, Mascot and Phenyx output files were processed by internally developed parsers. Proteins with $\geq 2$ unique peptides above a score T1, or with a single peptide above a score T2, were selected as unambiguous identifications. Additional peptides for these validated proteins with score > T3 were also accepted. For Mascot and Phenyx, T1, $\mathrm{T} 2$, and T3 peptide scores were equal to 16, 40, 10 and 5.5, 9.5, 3.5, respectively (p-value $<10^{-3}$ ). The validated proteins retrieved by the two algorithms were merged, any spectral conflicts discarded, and grouped according to shared peptides. A false positive detection rate (FDR) of $<1 \%$ and $<0.1 \%$ (including the peptides exported with lower scores) was determined for proteins and peptides, respectively, by applying the same procedure against a reversed database.

\section{Bioinformatic analysis - array data}

Gene expression study was performed with Agilent Whole Genome Microarrays (Agilent's SurePrint G3 Mouse GE $8 \times 60 \mathrm{~K}$ Microarray, Agilent Microarray Design ID 028005). The data analysis was performed using GeneSpring software 11.5 (Agilent Technologies). According to the manufacturer, the array contains 39,430 RNAs from Entrez Gene and 16,251 lincRNAs. The lincRNAs were not considered in the analysis. The cutoffs for differential expression were set as absolute fold-change $>2$ and a corrected p-value of $<$ 0.05 .

\section{Bioinformatic analysis - proteomics data}

Quantitative proteomics data was analyzed with isobar version 1.5.3 ${ }^{47}$. iTRAQ intensities were corrected for isotope impurities according to the instructions provided by the manufacturer, and channels normalized to equal summed intensities. Protein identifications were grouped by peptides, and only group-specific peptides were used for quantitation. In total, 5167 protein groups were identified, and 5138 quantitated. The intra-class ratios were calculated (114:115 and 116:117) to estimate the biological variability and fit a Tdistribution. The HDAC1-2 cKO/WT ratios were summarized from inter-class ratios, and proteins selected as significantly different that passed all of the following criteria: ratio $\mathrm{p}$ value $<0.05$, FDR adjusted sample p-value $<0.05$, fold change $>1.3$. With these criteria, 206 up-regulated and 49 down-regulated proteins in HDAC1-2 cKO compared to WT were selected from 5,138 quantitated proteins.

\section{Bioinformatic - comparison array data and proteomic data}

The mapping from probe IDs to gene product was performed using the GEO Platform file for the microarray (GPL10787) and Ensembl Biomart (version 72, accessed using the R package biomaRt 2.16.0). 31185 cDNAs could be mapped to Uniprot accession codes. 4760 of the 5167 protein group IDs from the proteomic experiment could be matched to 
microarray probe IDs. A subset of protein ACs matched to multiple probe IDs (due to splice variants and incorrect annotations) and these were further processed to generate a unique mapping: (1) matches where the gene name differed between transcript and protein (as stated in the GPL and Uniprot) were removed; (2) remaining rows were summarized (average ratio), unless the mRNA ratios were considered significant. Correlation of the logratios is in the expected range for microarray transcriptomic versus proteomics data ${ }^{48}$. The pearson's correlation coefficient was 0.4357 , and spearman's rank coefficient was 0.4219 . Out of the subset of significantly different species, 134 transcripts could be matched to proteomic, and 238 proteins to transcriptomic data.

\section{Statistical analysis}

No statistical methods were used to predetermine the sample size. The data shown are expressed as mean $\pm \mathrm{SD}$ or as mean \pm SEM (as indicated in the figure legends). All experiments that required a statistical analysis were performed at least three times. The statistical analyses were performed using Prism Software (GraphPad Inc). As indicated in each figure legend, P-values were calculated with either an unpaired two-tailed Student's t test (if data showed a Gaussian distribution; variances were assessed and if necessary an unpaired t-test with Welch's correction was applied), with an unpaired two-tailed MannWhitney test or with a Wilcoxon signed rank test. For qRTPCR expression data a normal distribution was assumed and data were analysed using an unpaired two-tailed Student's ttest (Fig. 5a and Supplementary Fig. 4b, indicated in the figure legends). The relative reduction in the percentage of $\mathrm{CD} 8^{+}$cells in Supplementary Fig. 5b was analysed using a one sample two-tailed t-test. No data were excluded and no specific randomization of animals or blinding of investigators was applied.

\section{Supplementary Material}

Refer to Web version on PubMed Central for supplementary material.

\section{ACKNOWLEDGMENTS}

The authors thank W. Glaser from the MFPL Genomics facility for performing the microarrays, D. Printz from St. Anna Children's hospital for cell sorting, C. Humer for help with immunoblot analysis and E. Pfeiffer for help with irradiation. We also thank R. Bosselut for the anti-Th-POK antibody and J. Zhu for the GATA3 vector. This study was funded by the Vienna Science and Technology Fund (WWTF) through project LS09-031 (to W.E. and C.S.). This work in the laboratory of W.E. was also supported by the Austrian Science Fund (FWF) and MedUni Vienna doctoral program (DK W1212) "inflammation and Immunity" and by FWF projects (P19930, P23641, I00698). The work in the laboratory of C.S. was supported by the FWF (P25807 and DKplus W1220) and the GEN-AU project "Epigenetic Regulation of Cell Fate Decisions" (BM:WF). N.B. and S.S. are funded by the FWF (P24265 and P23669, respectively). L.G. has been supported from the Innovative Medicines Initiative Joint Undertaking under grant agreement $n^{\circ} 115142$ (BTCure), resources of which are composed of financial contribution from the FP7 of the European Union and EFPIA companies' in kind contribution.

\section{REFERENCES}

1. Brunmeir R, Lagger S, Seiser C. Histone deacetylase HDAC1/HDAC2-controlled embryonic development and cell differentiation. Int J Dev Biol. 2009; 53:275-289. [PubMed: 19412887]

2. Haberland M, Montgomery RL, Olson EN. The many roles of histone deacetylases in development and physiology: implications for disease and therapy. Nat Rev Genet. 2009; 10:32-42. [PubMed: 19065135] 
3. Villagra A, Sotomayor EM, Seto E. Histone deacetylases and the immunological network: implications in cancer and inflammation. Oncogene. 2010; 29:157-173. [PubMed: 19855430]

4. Shakespear MR, Halili MA, Irvine KM, Fairlie DP, Sweet MJ. Histone deacetylases as regulators of inflammation and immunity. Trends Immunol. 2011; 32:335-343. [PubMed: 21570914]

5. Hancock WW, Akimova T, Beier UH, Liu Y, Wang L. HDAC inhibitor therapy in autoimmunity and transplantation. Ann Rheum Dis. 2012; 71(Suppl 2):i46-54. [PubMed: 22460138]

6. Grausenburger R, et al. Conditional deletion of histone deacetylase 1 in $\mathrm{T}$ cells leads to enhanced airway inflammation and increased Th2 cytokine production. J Immunol. 2010; 185:3489-3497. [PubMed: 20702731]

7. LeBoeuf M, et al. Hdac1 and Hdac2 act redundantly to control p63 and p53 functions in epidermal progenitor cells. Dev Cell. 2010; 19:807-818. [PubMed: 21093383]

8. Montgomery RL, Hsieh J, Barbosa AC, Richardson JA, Olson EN. Histone deacetylases 1 and 2 control the progression of neural precursors to neurons during brain development. Proc Natl Acad Sci U S A. 2009; 106:7876-7881. [PubMed: 19380719]

9. Wilting RH, et al. Overlapping functions of Hdac1 and Hdac2 in cell cycle regulation and haematopoiesis. Embo J. 2010; 29:2586-2597. [PubMed: 20571512]

10. Yamaguchi T, et al. Histone deacetylases 1 and 2 act in concert to promote the G1-to-S progression. Genes Dev. 2010; 24:455-469. [PubMed: 20194438]

11. Kasler HG, et al. Histone deacetylase 7 regulates cell survival and TCR signaling in CD4/CD8 double-positive thymocytes. J Immunol. 2011; 186:4782-4793. [PubMed: 21398603]

12. Kasler HG, et al. Nuclear export of histone deacetylase 7 during thymic selection is required for immune self-tolerance. Embo J. 2012; 31:4453-4465. [PubMed: 23103766]

13. Konkel JE, et al. Control of the development of CD8alphaalpha+ intestinal intraepithelial lymphocytes by TGF-beta. Nat Immunol. 2011; 12:312-319. [PubMed: 21297643]

14. Ellmeier W, Sunshine MJ, Losos K, Hatam F, Littman DR. An enhancer that directs lineagespecific expression of CD8 in positively selected thymocytes and mature T cells. Immunity. 1997; 7:537-547. [PubMed: 9354474]

15. Hostert A, et al. A region in the CD8 gene locus that directs expression to the mature CD8 T cell subset in transgenic mice. Immunity. 1997; 7:525-536. [PubMed: 9354473]

16. Hassan H, et al. Cd8 enhancer E8I and Runx factors regulate CD8alpha expression in activated CD8+ T cells. Proc Natl Acad Sci U S A. 2011; 108:18330-18335. [PubMed: 22025728]

17. Glimcher LH, Townsend MJ, Sullivan BM, Lord GM. Recent developments in the transcriptional regulation of cytolytic effector cells. Nat Rev Immunol. 2004; 4:900-911. [PubMed: 15516969]

18. Cruz-Guilloty F, et al. Runx3 and T-box proteins cooperate to establish the transcriptional program of effector CTLs. J Exp Med. 2009; 206:51-59. [PubMed: 19139168]

19. Rui J, Liu H, Zhu X, Cui Y, Liu X. Epigenetic Silencing of Cd8 Genes by ThPOK-Mediated Deacetylation during CD4 T Cell Differentiation. J Immunol. 2012; 189:1380-1390. [PubMed: 22730529]

20. Jenkinson SR, et al. Expression of the transcription factor cKrox in peripheral CD8 T cells reveals substantial postthymic plasticity in CD4-CD8 lineage differentiation. J Exp Med. 2007; 204:267272. [PubMed: 17296789]

21. Egawa T, Littman DR. ThPOK acts late in specification of the helper T cell lineage and suppresses Runx-mediated commitment to the cytotoxic T cell lineage. Nat Immunol. 2008; 9:1131-1139. [PubMed: 18776905]

22. Wang $\mathrm{L}$, et al. The zinc finger transcription factor $\mathrm{Zbtb} 7 \mathrm{~b}$ represses $\mathrm{CD} 8$-lineage gene expression in peripheral CD4+ T cells. Immunity. 2008; 29:876-887. [PubMed: 19062319]

23. Muroi $\mathrm{S}$, et al. Cascading suppression of transcriptional silencers by ThPOK seals helper T cell fate. Nat Immunol. 2008; 9:1113-1121. [PubMed: 18776907]

24. Taniuchi I, et al. Differential requirements for Runx proteins in CD4 repression and epigenetic silencing during T lymphocyte development. Cell. 2002; 111:621-633. [PubMed: 12464175]

25. Dokmanovic M, Clarke C, Marks PA. Histone deacetylase inhibitors: overview and perspectives. Mol Cancer Res. 2007; 5:981-989. [PubMed: 17951399] 
26. Naoe Y, et al. Repression of interleukin-4 in T helper type 1 cells by Runx/Cbf beta binding to the Il4 silencer. J Exp Med. 2007; 204:1749-1755. [PubMed: 17646405]

27. Sato T, et al. Dual functions of Runx proteins for reactivating CD8 and silencing CD4 at the commitment process into CD8 thymocytes. Immunity. 2005; 22:317-328. [PubMed: 15780989]

28. Balasubramanyam K, Swaminathan V, Ranganathan A, Kundu TK. Small molecule modulators of histone acetyltransferase p300. J Biol Chem. 2003; 278:19134-19140. [PubMed: 12624111]

29. Yagi R, et al. The transcription factor GATA3 actively represses RUNX3 protein-regulated production of interferon-gamma. Immunity. 2010; 32:507-517. [PubMed: 20399120]

30. Yagi R, Zhu J, Paul WE. An updated view on transcription factor GATA3-mediated regulation of Th1 and Th2 cell differentiation. Int Immunol. 2011; 23:415-420. [PubMed: 21632975]

31. Choudhary $\mathrm{C}$, et al. Lysine acetylation targets protein complexes and co-regulates major cellular functions. Science. 2009; 325:834-840. [PubMed: 19608861]

32. Ellmeier W, Sunshine MJ, Maschek R, Littman DR. Combined deletion of CD8 locus cisregulatory elements affects initiation but not maintenance of CD8 expression. Immunity. 2002; 16:623-634. [PubMed: 12049715]

33. He X, et al. The zinc finger transcription factor Th-POK regulates CD4 versus CD8 T-cell lineage commitment. Nature. 2005; 433:826-833. [PubMed: 15729333]

34. Sun G, et al. The zinc finger protein cKrox directs CD4 lineage differentiation during intrathymic T cell positive selection. Nat Immunol. 2005; 6:373-381. [PubMed: 15750595]

35. Zhang M, Zhang J, Rui J, Liu X. p300-mediated acetylation stabilizes the Th-inducing POK factor. J Immunol. 2010; 185:3960-3969. [PubMed: 20810990]

36. Pozzesi N, et al. Role of caspase-8 in thymus function. Cell death and differentiation. 2013

\section{REFERENCES ONLY INCLUDED IN THE ONLINE METHODS}

37. Ellmeier W, Sunshine MJ, Losos K, Littman DR. Multiple developmental stage-specific enhancers regulate CD8 expression in developing thymocytes and in thymus-independent T cells. Immunity. 1998; 9:485-496. [PubMed: 9806635]

38. Bartl S, et al. Identification of mouse histone deacetylase 1 as a growth factor-inducible gene. Mol. Cell. Biol. 1997; 17:5033-5043. [PubMed: 9271381]

39. Tayade C, et al. Differential transcription of Eomes and T-bet during maturation of mouse uterine natural killer cells. J Leukoc Biol. 2005; 78:1347-1355. [PubMed: 16204645]

40. Yang Y, Ochando JC, Bromberg JS, Ding Y. Identification of a distant T-bet enhancer responsive to IL-12/Stat4 and IFNgamma/Stat1 signals. Blood. 2007; 110:2494-2500. [PubMed: 17575072]

41. Sakaguchi S, et al. The zinc-finger protein MAZR is part of the transcription factor network that controls the CD4 versus CD8 lineage fate of double-positive thymocytes. Nat Immunol. 2010; 11:442-448. [PubMed: 20383150]

42. Djuretic IM, et al. Transcription factors T-bet and Runx3 cooperate to activate Ifng and silence Il4 in T helper type 1 cells. Nat Immunol. 2007; 8:145-153. [PubMed: 17195845]

43. Wisniewski JR, Zougman A, Nagaraj N, Mann M. Universal sample preparation method for proteome analysis. Nat Methods. 2009; 6:359-362. [PubMed: 19377485]

44. Maurer M, et al. Combining filter-aided sample preparation and pseudoshotgun technology to profile the proteome of a low number of early passage human melanoma cells. J Proteome Res. 2013; 12:1040-1048. [PubMed: 23214492]

45. Bennett KL, et al. Proteomic analysis of human cataract aqueous humour: Comparison of onedimensional gel LCMS with two-dimensional LCMS of unlabelled and iTRAQ(R)-labelled specimens. J Proteomics. 2011; 74:151-166. [PubMed: 20940065]

46. Colinge J, Masselot A, Giron M, Dessingy T, Magnin J. OLAV: towards high-throughput tandem mass spectrometry data identification. Proteomics. 2003; 3:1454-1463. [PubMed: 12923771]

47. Breitwieser FP, et al. General statistical modeling of data from protein relative expression isobaric tags. J Proteome Res. 2011; 10:2758-2766. [PubMed: 21526793]

48. Vogel C, Marcotte EM. Insights into the regulation of protein abundance from proteomic and transcriptomic analyses. Nat Rev Genet. 2012; 13:227-232. [PubMed: 22411467] 


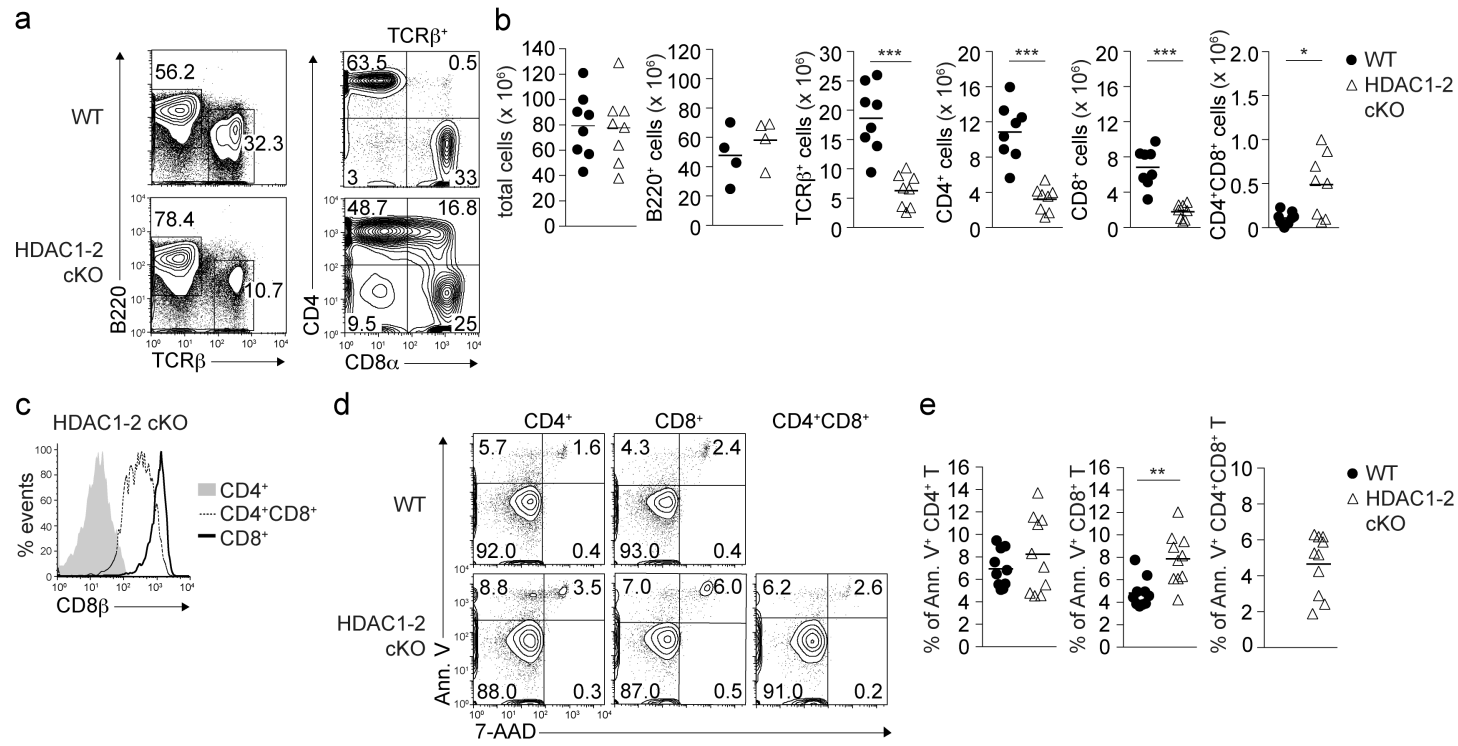

Figure 1.

Altered $\mathrm{T}$ cell subsets in mice with a T cell-specific loss of HDAC1 and HDAC2. (a) Flow cytometry analysis of $\mathrm{B} 220, \mathrm{TCR} \beta, \mathrm{CD} 4$ and $\mathrm{CD} 8 \mathrm{a}$ expression on splenocytes isolated from WT and HDAC1-2 cKO mice. (b) Absolute numbers of all cells, B220 $0^{+} \mathrm{B}$ cells, TCR $\beta^{+} \mathrm{T}$ cells, $\mathrm{CD} 4^{+} \mathrm{T}$ cells, $\mathrm{CD} 8^{+} \mathrm{T}$ cells and $\mathrm{CD} 4^{+} \mathrm{CD} 8^{+} \mathrm{T}$ cells in the spleens of WT and HDAC1-2 cKO mice. (c) Flow cytometry analysis of CD $8 \beta$ expression in $\mathrm{CD} 4^{+} \mathrm{CD} 8^{+} \mathrm{T}$ cells isolated from the spleen of HDAC1-2 cKO mice. (d-e) Representative flow cytometry analysis (d) and summary (e) of Annexin $\mathrm{V}$ and 7-AAD staining on peripheral splenic CD4 ${ }^{+}$ $\mathrm{T}$ cells, $\mathrm{CD} 8^{+} \mathrm{T}$ cells and $\mathrm{CD} 4{ }^{+} \mathrm{CD} 8^{+} \mathrm{T}$ cells isolated from WT and HDAC1- 2 cKO mice. (a, d) Numbers indicate the percentage of cells in the respective quadrants. (b,e) Thick horizontal bars indicate the mean. (b) $* \mathrm{P}<0.05$ and $* * * \mathrm{P}<0.001$ (unpaired two-tailed Student's t-test, except for B220 ${ }^{+}$cells (unpaired Mann-Whitney test)). (e) $* * \mathrm{P}<0.01$ (unpaired two-tailed Mann-Whitney test). Data are representative (a,c,d) or show the summary (b,e) of five mice (a,c), of eight mice (except for B220 ${ }^{+}$cells with four mice) and of ten mice (e) that were analyzed in two $(\mathbf{a}, \mathbf{b})$ and three (c-e) independent experiments. 
a
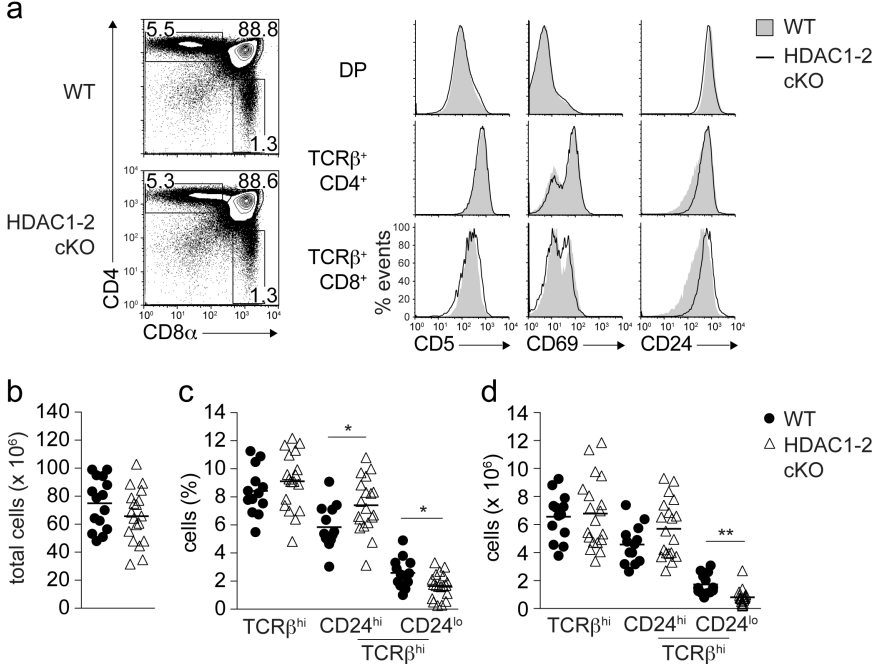

d

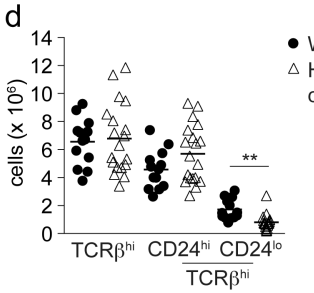

e

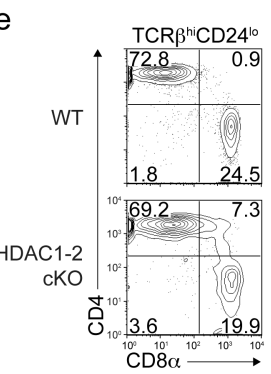

$f$

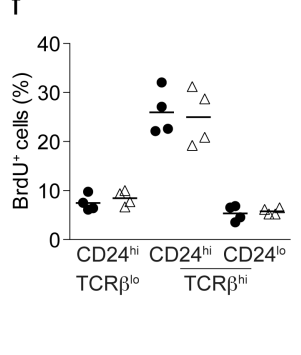

g

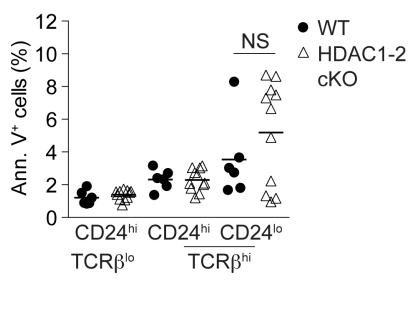

Figure 2.

Mature TCR $\beta^{\text {hi }} \mathrm{CD} 24^{\text {lo }} \mathrm{SP}$ cells are reduced in HDAC1-2 cKO mice. (a) Flow cytometry analysis of CD4 and CD8a expression on WT and HDAC1-2 cKO thymocytes, and of CD5, CD69 and CD24 expression on DP, TCR $\beta^{\text {hi }} \mathrm{CD} 4^{+}$and TCR $\beta{ }^{\text {hi }} \mathrm{CD} 8^{+}$thymocyte subsets. (b) Absolute thymocyte numbers in WT and HDAC1-2 cKO mice. (c,d) Percentages (c) and absolute cell numbers (d) of TCR $\beta^{\text {hi }}$, TCR $\beta^{\text {hi }}$ CD $24^{\text {hi }}$ and TCR $\beta^{\text {hi }}$ CD $24^{\text {lo }}$ WT and HDAC1-2 cKO thymocyte subsets. (e) Flow cytometry analysis of CD4 and CD8a expression on WT and HDAC1-2 cKO TCR $\beta^{\text {hi }}$ CD2 $4^{\text {lo }}$ thymocytes. (f) Summary of BrdU incorporation in TCR $\beta^{\text {lo }} \mathrm{CD} 24^{\text {hi }}$, TCR ${ }^{\text {hi }} \mathrm{CD} 24^{\text {hi }}$ and TCR ${ }^{\text {hi }} \mathrm{CD} 24^{\text {lo }}$ thymocyte subsets in WT and HDAC1-2 cKO mice. (g) Percentage of Annexin $\mathrm{V}^{+}$cells in TCR $\beta^{\mathrm{lo}} \mathrm{CD} 24^{\mathrm{hi}}$, TCR $\beta{ }^{\mathrm{hi}} \mathrm{CD} 24^{\mathrm{hi}}$ and TCR $\beta^{\text {hi }} \mathrm{CD} 24^{\text {lo }}$ WT and HDAC1-2 cKO thymocyte subsets. (a,e) Numbers in the contour plot quadrants indicate the percentage of cells. (b-d,f,g) Horizontal bars indicate the mean. Data are representative (a,e) or show the summary (b-d,f,g) of thirteen (WT) and nineteen (HDAC1-2 cKO) mice except for CD5 (four mice) and CD69, CD24 (five mice) (a-d), of ten mice (e), of four mice (f) and of six (WT) and eleven (HDAC1-2 cKO) mice (g) that were analyzed in two to five (a), four (b-d), two (f) and three (g) independent experiments. (c) $* \mathrm{P}<0.05$ (unpaired two-tailed Student's t-test). (d) **P $<0.001$ (unpaired two-tailed Mann-Whitney test). (g) NS, not significant (unpaired two-tailed Mann-Whitney test). 


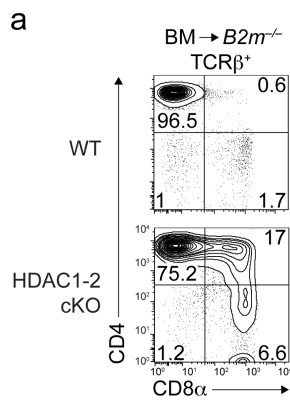

C
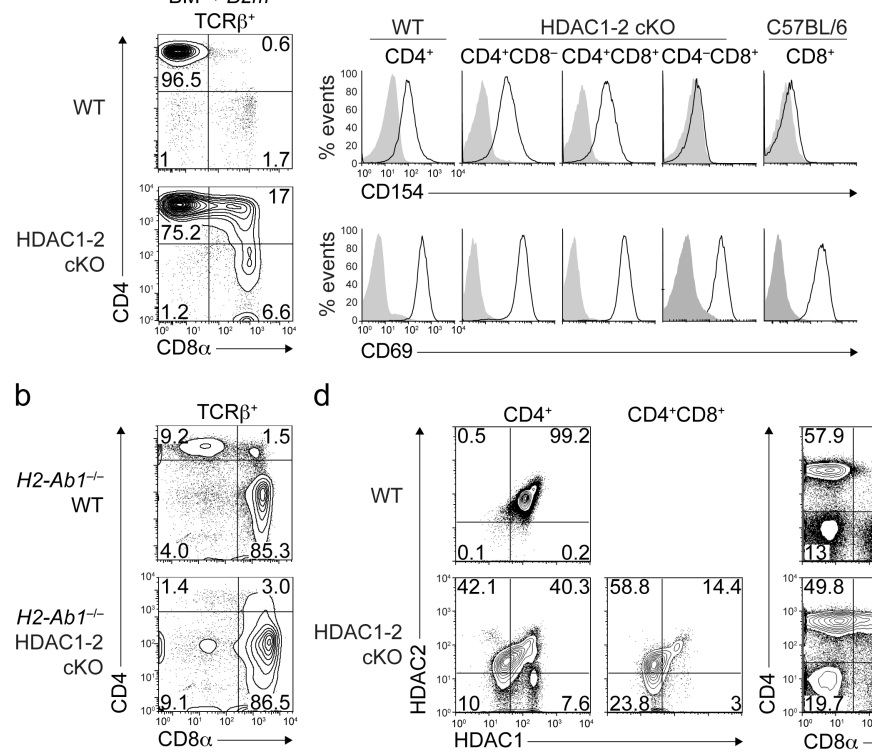

d
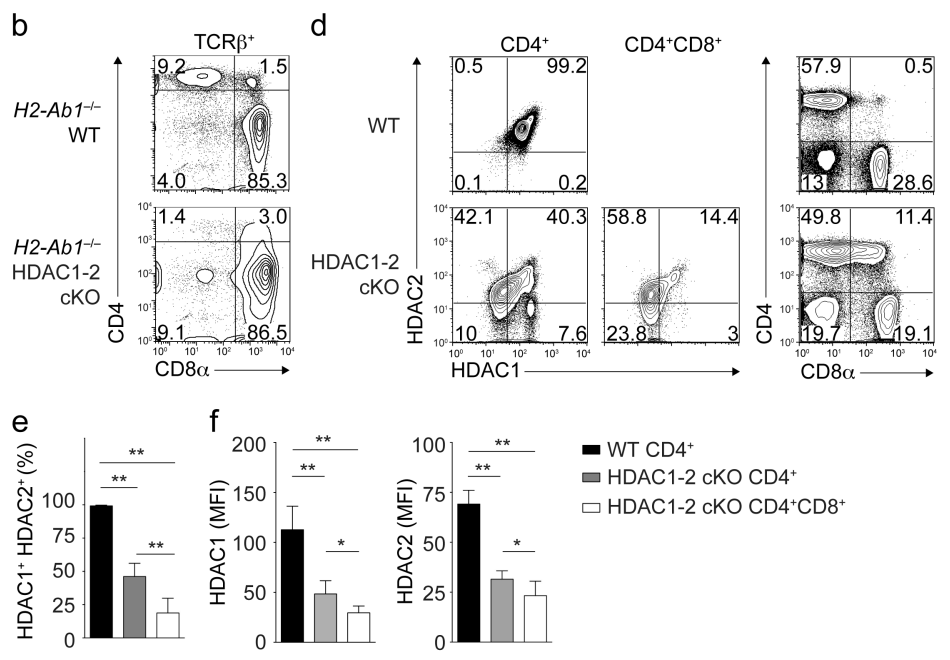

$\mathrm{f}$
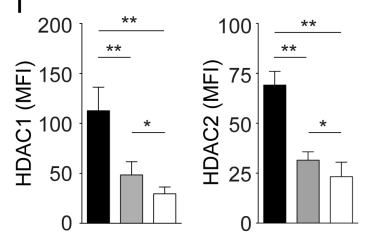

- WT CD4 ${ }^{+}$

$\square$ HDAC1-2 CKO CD4 ${ }^{+}$

$\square$ HDAC1-2 CKO CD4 $4^{+} \mathrm{CD} 8^{+}$

Figure 3.

HDAC1-2 $\mathrm{cKO} \mathrm{CD} 4^{+} \mathrm{CD} 8^{+} \mathrm{T}$ cells are MHC class II-selected and up-regulate $\mathrm{CD} 154$ upon activation. (a) Flow cytometry analysis of CD4 and CD8a expression on TCR $\beta^{+}$splenocytes isolated from WT and HDAC1-2 cKO BM chimeric $B 2 \mathrm{~m}^{-/-}$mice. (b) Flow cytometry analysis of CD4 and CD8a expression on $\mathrm{H2}-\mathrm{Abl}^{-/-} \mathrm{WT}$ or $\mathrm{H2}-\mathrm{Ab} \mathrm{I}^{-/-} \mathrm{HDAC} 1-2 \mathrm{cKO}$ TCR $\beta^{+}$splenocytes. (c) Flow cytometry analysis of CD154 and CD69 expression on WT and HDAC1-2 cKO CD4 ${ }^{+} \mathrm{T}$ cells and on HDAC1-2 cKO CD4 ${ }^{+} \mathrm{CD} 8^{+} \mathrm{T}$ cells and $\mathrm{CD} 8^{+} \mathrm{T}$ cells isolated from WT and HDAC1-2 cKO BM chimeric $B 2 m^{-/-}$mice, or on $\mathrm{CD} 8^{+} \mathrm{T}$ cells isolated from C57BL/6 mice. Cells were activated with anti-CD3 and anti-CD28 for 24 hours. (d) Flow cytometry analysis of intracellular HDAC1 and HDAC2 expression in WT and HDAC1-2 cKO CD4 ${ }^{+} \mathrm{T}$ cells, and in HDAC1-2 cKO CD4 ${ }^{+} \mathrm{CD} 8{ }^{+} \mathrm{T}$ cells. The $\mathrm{CD} 4$ and CD8 a contour plots of WT and HDAC1-2 cKO TCR $\beta^{+}$splenocytes indicate gating areas. (e) Percentage of HDAC1 and HDAC2 expressing WT CD4 ${ }^{+}$T cells, HDAC1-2 cKO CD4 ${ }^{+}$ $\mathrm{T}$ cells and $\mathrm{HDAC} 1-2 \mathrm{cKO} \mathrm{CD} 4^{+} \mathrm{CD} 8{ }^{+} \mathrm{T}$ cells. Cells were gated on the upper-right quadrant of the HDAC1-HDAC2 contour plots shown in (d). (f) Mean fluorescence intensity (MFI) of HDAC1 and HDAC2 expression in $\mathrm{WT} \mathrm{CD}^{+} \mathrm{T}$ cells, and in HDAC1-2 cKO $\mathrm{CD} 4^{+} \mathrm{T}$ cells and $\mathrm{CD} 4^{+} \mathrm{CD} 8^{+} \mathrm{T}$ cells. $(\mathbf{a}, \mathbf{b}, \mathbf{d})$ Numbers in quadrants indicate the percentage of cells. Data are representative (a-d) or show the summary (e,f) of six BM chimeric $B 2 \mathrm{~m}^{-/-}$mice (a), of three mice (b), of two independent samples (c) and of nine (WT) and ten (HDAC1-2 cKO) mice (d-f) analyzed in two (a-c) or three (d-f) independent experiments. (e) **P $<0.01$ (unpaired two-tailed Mann-Whitney test). (f) $* \mathrm{P}<0.05$ and **P $<0.001$ (unpaired two-tailed Mann-Whitney test). Mean \pm SD is shown. 
a

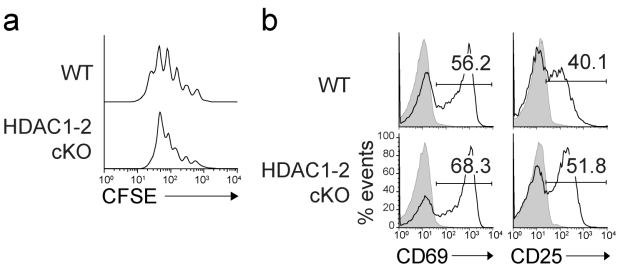

d

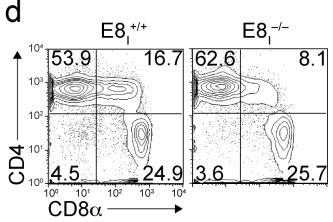

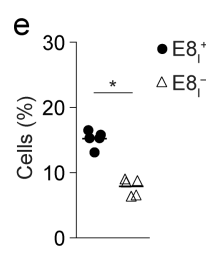

Figure 4. Whitney test).
C

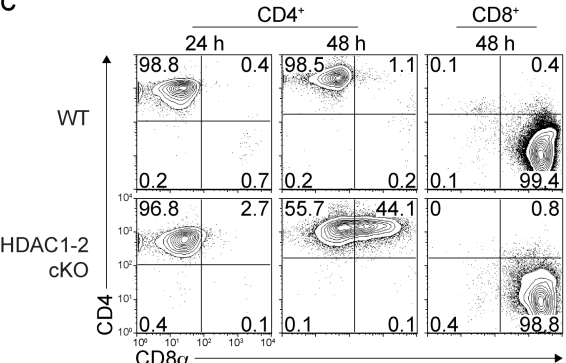

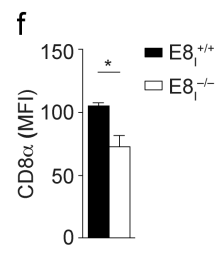

g

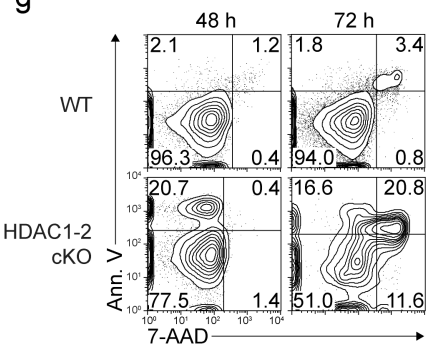

$\mathrm{CD}^{+} \mathrm{T}$ cells from HDAC1-2 cKO mice up-regulate $\mathrm{CD} 8$ upon activation. (a) Flow cytometry analysis showing cell divisions of CFSE-labeled WT and HDAC1-2 cKO CD4 ${ }^{+} \mathrm{T}$ cells activated with anti-CD3 and anti-CD28 for 2.5 days. (b) Flow cytometry analysis of CD69 and CD25 expression on WT and HDAC1-2 cKO CD4 ${ }^{+}$T cells activated with anti$\mathrm{CD} 3$ and anti-CD28 for 16 hours. Grey areas indicate non-activated $\mathrm{CD} 4^{+} \mathrm{T}$ cells. (c) Flow cytometric analysis of CD4 and CD8a expression on WT and HDAC1-2 cKO CD4 $4^{+}$and $\mathrm{CD}^{+} \mathrm{T}$ cells activated with anti-CD3 and anti-CD28 for 24 and 48 hours. (d,e) Representative flow cytometry analysis (d) and summary (e) of CD4 and CD8a expression on $\mathrm{TCR} \beta^{+}$splenocytes from $\mathrm{E}_{\mathrm{I}}{ }^{+/+} \mathrm{HDAC} 1-2 \mathrm{cKO}\left(\mathrm{E}_{\mathrm{I}}{ }^{+/+}\right)$and $\mathrm{E} 8_{\mathrm{I}}{ }^{-/} \mathrm{HDAC} 1-2 \mathrm{cKO}$ $\left(\mathrm{E}^{-}{ }^{-/}\right)$mice. (f) Mean fluorescence intensity (MFI) of CD8a expression on $\mathrm{E} 8 \mathrm{I}^{+/+} \mathrm{HDAC} 1-2 \mathrm{cKO}$ and $\mathrm{E} 8{ }_{\mathrm{I}}^{-/-} \mathrm{HDAC} 1-2 \mathrm{cKO} \mathrm{CD} 4{ }^{+} \mathrm{CD} 8{ }^{+} \mathrm{T}$ cells. $\mathrm{CD} 4{ }^{+} \mathrm{CD} 8{ }^{+} \mathrm{T}$ cells were gated on the upper right quadrants of the CD4-CD8a contour plots shown in (d). (g) Flow cytometric analysis showing Annexin $\mathrm{V}$ and 7-AAD stainings on WT and HDAC1-2 cKO CD4 ${ }^{+} \mathrm{T}$ cells activated with anti-CD3 and anti-CD28 for 48 and 72 hours. (b,c,d,g) Numbers indicate the percentage of cells in the respective quadrant $(\mathbf{c}, \mathbf{d}, \mathbf{g})$ or histogram regions (b). Data are representative of two $(\mathbf{a}, \mathbf{b}, \mathbf{g})$ and three (c) independent samples and of five mice (d-f) that were analyzed in two (a,b,d-g) and three (c) experiments. (e) Horizontal bars indicate the mean. (f) Mean \pm SD is shown. (e,f) $* \mathrm{P}<0.01$ (unpaired two-tailed Mann- 


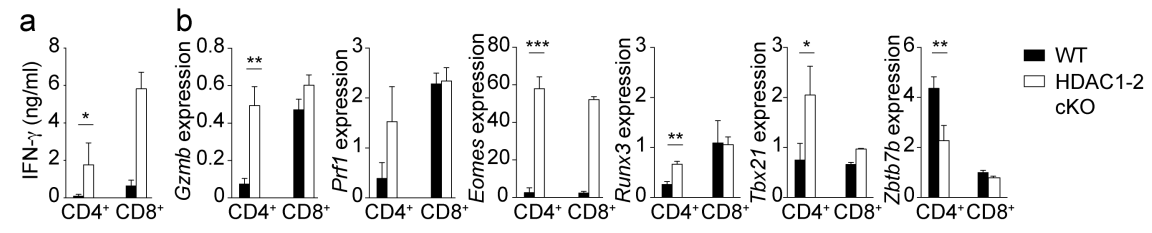

C

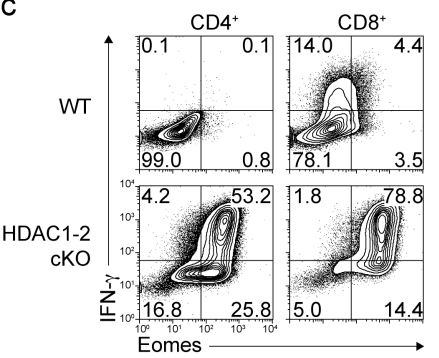

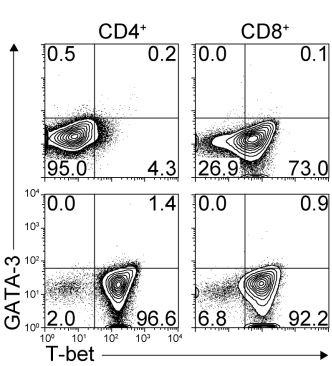

d

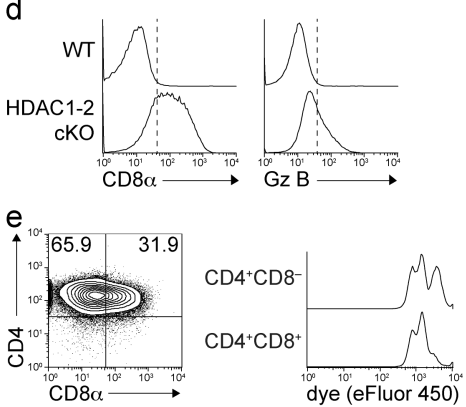

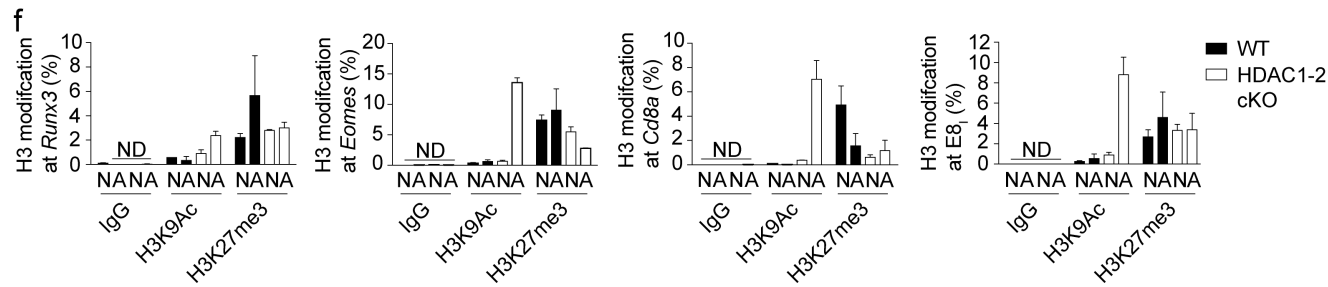

Figure 5.

A CD8 effector program is induced in activated HDAC1-2 cKO CD4 $4^{+} \mathrm{T}$ cells. (a) IFN- $\gamma$ in supernatants of WT and HDAC1- $2 \mathrm{cKO} \mathrm{CD} 4^{+}$and $\mathrm{CD}^{+} \mathrm{T}$ cells activated with anti-CD3 and anti-CD28 for 60 hours. *P $<0.05$ (unpaired two-tailed Mann-Whitney test). Mean \pm SD is shown. (b) qRTPCR analysis showing the expression of several genes in WT and HDAC1-2 $\mathrm{cKO} \mathrm{CD}^{+}$and $\mathrm{CD}^{+}{ }^{+} \mathrm{T}$ cells activated as described in (a). Expression relative to Hprt is shown. $* \mathrm{P}<0.05, * * \mathrm{P}<0.01, * * * \mathrm{P}<0.001$ (unpaired two-tailed Student's t-test). Mean \pm SD is shown. (c,d) Flow cytometric analysis showing intracellular expression of IFN- $\gamma$ and Eomesodermin and of GATA-3 and T-bet (c) and of Granzyme B (Gz B) and surface expression of CD8a (d) in WT and HDAC1-2 cKO CD4 ${ }^{+}$and $\mathrm{CD}^{+}{ }^{+} \mathrm{T}$ cells activated as described in (a). (e) Flow cytometry analysis showing cell divisions of cell division dye Efluor-V450-labeled naive HDAC1-2 $\mathrm{cKO} \mathrm{CD} 4^{+} \mathrm{T}$ cells activated as described in (a). Cells were gated on $\mathrm{CD} 4{ }^{+} \mathrm{CD} 8 \mathrm{a}^{-}$and $\mathrm{CD}^{+}{ }^{+} \mathrm{CD} 8 \mathrm{a}^{+}$subsets. (f) qRTPCR analysis with primers specific for Runx3, Eomes and $C d 8 a$ promoter regions and for $C d 8$ enhancer E8 I from chromatin of non-activated $(\mathrm{N})$ and activated (A; anti-CD3 plus anti-CD28 for 60 hours) WT and HDAC1-2 cKO CD4 ${ }^{+} \mathrm{T}$ cells immunoprecipitated with anti-H3K9Ac or anti-H3K27me3 antibodies (or IgG as control). Mean \pm SD is shown. Values are corrected to $\mathrm{H} 3$ levels and shown as \% input. (c, e) Numbers in contour plots indicate the percentage of cells in the respective quadrant. Data are representative (c-f) or show the summary (a,b) of four $(\mathbf{a}, \mathbf{e})$, of three $\left(\mathrm{CD} 4^{+} \mathrm{T}\right.$ cells $)$ and two $\left(\mathrm{CD}^{+} \mathrm{T}\right.$ cells $)(\mathbf{b})$ and of two $(\mathbf{c}, \mathbf{d , f})$ independent samples that were analyzed in three $(\mathbf{a})$, in two $\left(\mathrm{CD}^{+}{ }^{+} \mathrm{T}\right.$ cells) and one $\left(\mathrm{CD} 8^{+}\right.$ T cells) (b) and in two (c-f) independent experiments. 
a

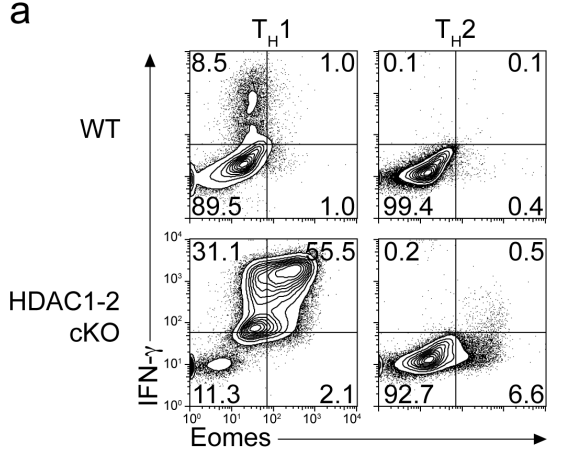

b

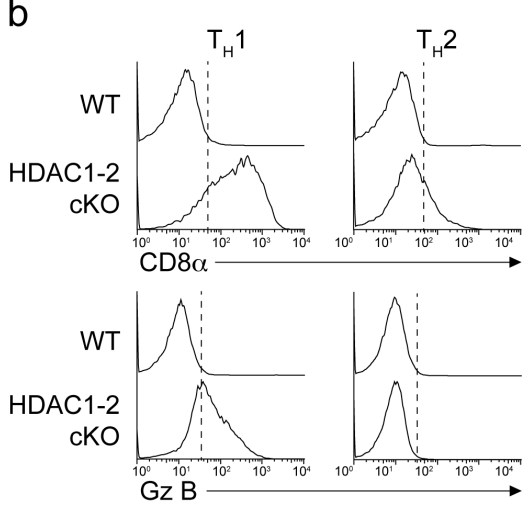

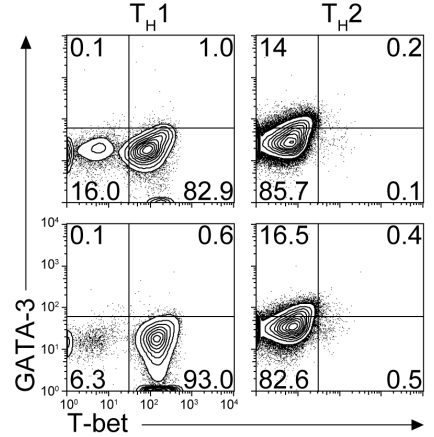

C

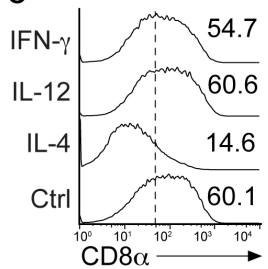

Figure 6.

A CD8 effector program is induced in HDAC1-2 cKO $\mathrm{T}_{\mathrm{H}} 1$ but not in $\mathrm{T}_{\mathrm{H}} 2$ cells. (a) Flow cytometry analysis showing intracellular expression of IFN- $\gamma$ and Eomesodermin and of GATA-3 and T-bet in naive WT and HDAC1-2 cKO CD4 ${ }^{+}$T cells activated with anti-CD3 and anti-CD28 for 60 hours in the presence of $\mathrm{T}_{\mathrm{H}} 1$ - and $\mathrm{T}_{\mathrm{H}} 2$-polarizing conditions. (b) Flow cytometry analysis showing intracellular Granzyme B $(\mathrm{Gz} B)$ and surface CD8a expression in WT and HDAC1-2 cKO CD4 ${ }^{+} \mathrm{T}$ cells activated as described in (a). (c) Flow cytomety analysis showing CD8a expression on naive HDAC1-2 cKO CD4 ${ }^{+} \mathrm{T}$ cells activated with anti-CD3 and anti-CD28 for 60 hours in the presence of IFN- $\gamma$, IL-12, IL-4 or without the addition of cytokines (control; Ctrl). (a-c) Numbers indicate the percentage of cells in the (a) respective quadrant or in (b,d) histograms. (a-c) Data are representative of two independent samples analyzed in two $(\mathbf{a}, \mathbf{b})$ or one $(\mathbf{c})$ experiments. 

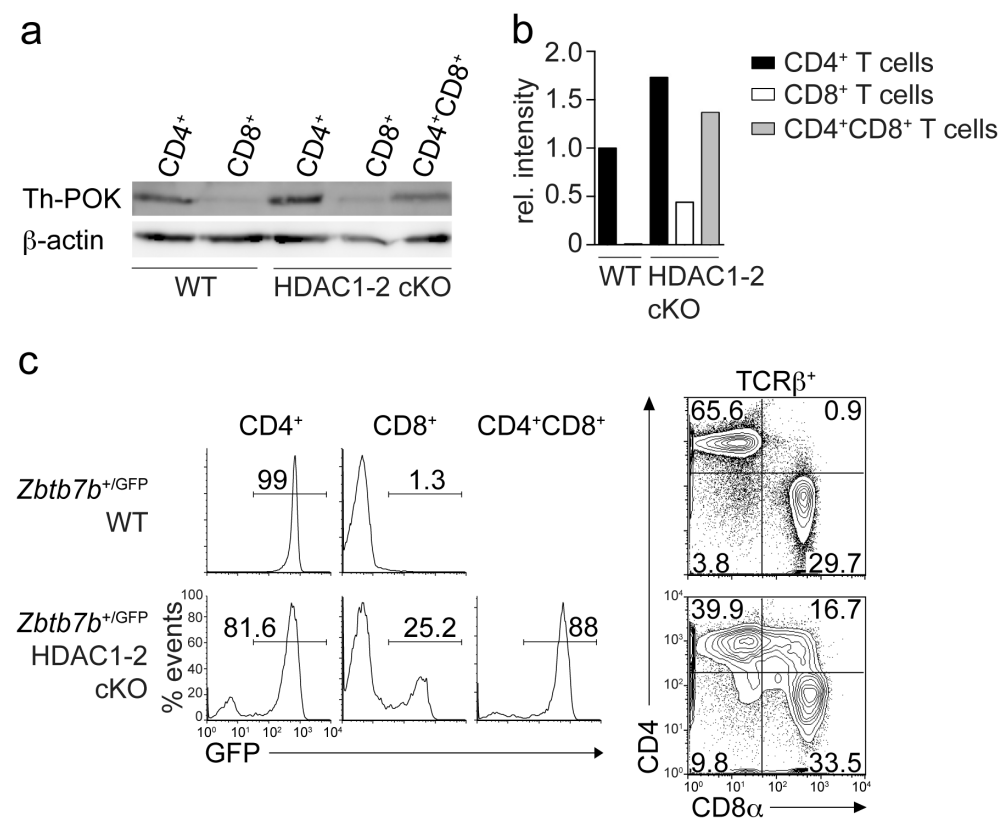

Figure 7.

Th-POK expression in HDAC1-2 cKO CD4 $4^{+} \mathrm{T}$ cells. (a) Immunoblot showing Th-POK expression in $\mathrm{WT} \mathrm{CD}^{+}$and $\mathrm{CD} 8^{+} \mathrm{T}$ cells and in $\mathrm{HDAC} 1-2 \mathrm{cKO} \mathrm{CD} 4^{+}, \mathrm{CD} 8^{+}$and $\mathrm{CD} 4^{+} \mathrm{CD} 8^{+} \mathrm{T}$ cells. Whole cell lysates from approx. $3 \times 10^{5}$ cells were loaded and $\beta$-Actin was used as loading control. (b) Quantification of the immunoblot shown in (a). Th-POK expression was normalized to $\beta$-Actin. Th-POK expression in $\mathrm{WT} \mathrm{CD}^{+}$was set as 1 and relative intensities are shown. (c) Flow cytometry analysis showing GFP expression in WT $\mathrm{CD}^{+}$and $\mathrm{CD} 8^{+} \mathrm{T}$ cells and in HDAC $1-2 \mathrm{cKO} \mathrm{CD} 4^{+}, \mathrm{CD} 8^{+}$and $\mathrm{CD} 4^{+} \mathrm{CD} 8^{+} \mathrm{T}$ cells. The $\mathrm{CD} 4$ and CD8a contour plots of $Z b t b 7 b^{+/ G F P} \mathrm{WT}$ and $Z b t b 7 b^{+/ G F P} \mathrm{HDAC} 1-2 \mathrm{cKO} \mathrm{TCR} \beta^{+}$ splenocytes indicate the gating regions. Numbers indicate the percentage of cells. (a-c) Data are representative of three independent samples $(\mathbf{a , b})$ and of five $\left(Z b t b 7 b^{+/ G F P} \mathrm{WT}\right)$ and ten $\left(Z b t b 7 b^{+/ G F P}\right.$ HDAC1-2 cKO) mice (c) performed in three (a,b) and two (c) independent experiments. 
a
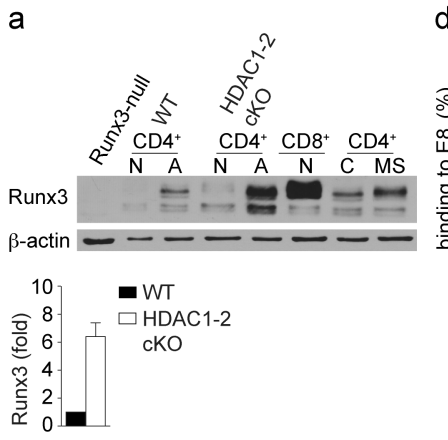

b

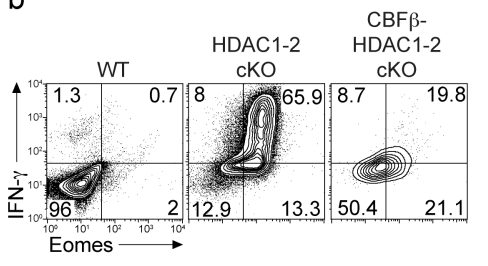

C

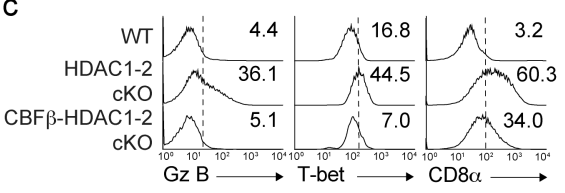

d

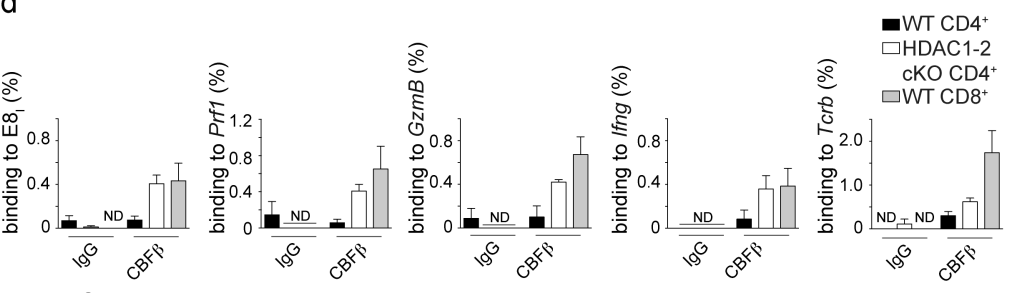

e

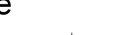

MIGR

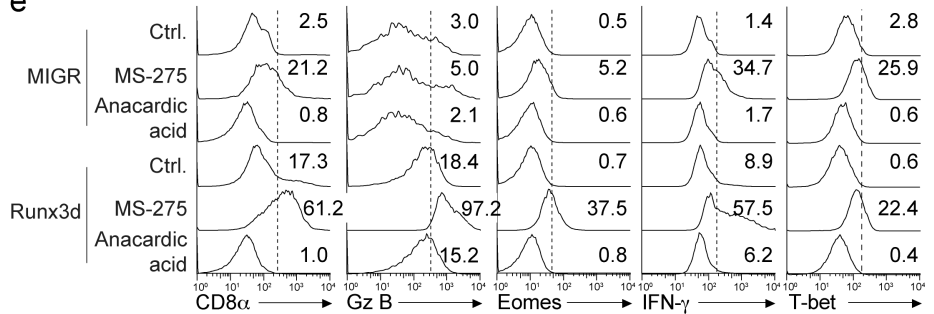

f

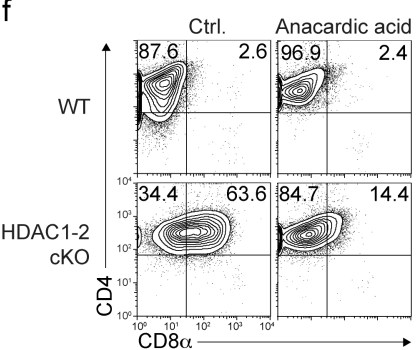

$\mathrm{g}$

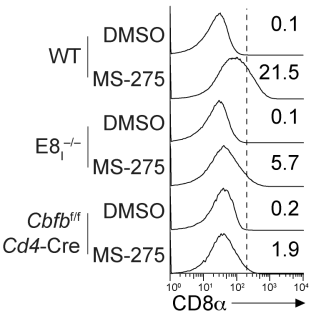

Figure 8.

The induction of CD8 lineage genes in HDAC1-2 cKO CD4 ${ }^{+} \mathrm{T}$ cells is dependent on RunxCBF $\beta$ complexes. (a) Immunoblot showing Runx3 expression in non-activated (N) and antiCD3 with anti-CD28 activated for 48h (A) WT and HDAC1-2 cKO CD4 ${ }^{+} \mathrm{T}$ cells. Whole cell lysates were loaded. Non-activated $R u n x 3^{3 / f} \mathrm{C} d 4$-Cre $\mathrm{CD} 4{ }^{+} \mathrm{T}$ cells (Runx3-null) or wildtype $\mathrm{CD}^{+} \mathrm{T}$ cells $\left(\mathrm{CD}^{+}\right)$were used as controls. Runx3 expression in activated wild-type $\mathrm{CD}^{+}{ }^{+} \mathrm{T}$ cells treated with MS-275 (MS) or DMSO as carrier control (C) is shown at the right. Diagram shows Runx3 expression (normalized to $\beta$-Actin) in activated HDAC1-2 cKO CD $4^{+} \mathrm{T}$ cells relative to activated WT CD4 ${ }^{+} \mathrm{T}$ cells (mean $\left.\pm \mathrm{SD}\right)(\mathbf{b}, \mathbf{c})$ Flow cytometry analysis showing intracellular expression of IFN- $\gamma$ and Eomesodermin (Eomes) (b) and intracellular expression of Granzyme B (Gz B) and T-bet expression and surface expression of CD8a (c) in naïve WT, HDAC1-2 cKO and CBFß-HDAC1-2 cKO CD4 ${ }^{+} \mathrm{T}$ cells activated with anti-CD3, anti-CD28 and hrIL-2 for 60 hours. (d) qRTPCR analysis with primers specific for Prfl, GzmB, Infg and Tcrb promoter regions and for $C d 8$ enhancer E8I from chromatin of activated (anti-CD3 with anti-CD28 for 48 hours) WT CD4 $4^{+}$and HDAC1- 2 cKO CD4 ${ }^{+} \mathrm{T}$ cells and from activated (anti-CD3 and anti-CD28 for 2 days, followed by 4 days rest) wild-type $\mathrm{CD} 8^{+} \mathrm{T}$ cells immunoprecipitated with anti-CBF $\beta$ antibody or with $\operatorname{IgG}$ as control. Values are shown as \% input. (e) Flow cytometry analysis showing surface CD8a and intracellular Granzyme B (Gz B), Eomesodermin (Eomes), IFN$\gamma$ and T-bet expression on $\mathrm{GFP}^{+}$wild-type $\mathrm{CD}^{+} \mathrm{T}$ cells 48 hours after transduction with either "empty" MIGR-control or with a Runx3d-containing retroviral vector. MS-275 (or DMSO as carrier control) or anacardic acid were added one day after transduction. (f) Flow cytometry analysis showing CD4 and CD8a expression on WT and HDAC1-2 cKO CD4 ${ }^{+} \mathrm{T}$ cells activated with anti-CD3 and anti-CD28 for 48 hours. Anacardic acid (or EtOH as 
carrier control; Ctrl.) was added 24 hours after activation. (g) Flow cytometry analysis of $\mathrm{CD} 4$ and CD8a expression on wild-type (C57BL/6), $\mathrm{E}_{\mathrm{I}}{ }^{-/-}$and $\mathrm{Cbfb}^{\mathrm{f} / \mathrm{f}} \mathrm{Cd} 4-\mathrm{Cre} \mathrm{CD} 4{ }^{+} \mathrm{T}$ cells activated with anti-CD3 and anti-CD28 activated for 48 hours. MS-275 was added 24h after activation. Data are representative (a-c,e-g) or show the summary (d) of two (a-c,f), of two (CD4 ${ }^{+} \mathrm{T}$ cells) and one (CD8 ${ }^{+} \mathrm{T}$ cells, two independent ChIP assays) $(\mathbf{d})$, of at least three (except two for IFN- $\gamma)(\mathbf{e})$ and of six (WT), three $\left(\mathrm{E}_{\mathrm{I}}^{-{ }^{-}}\right)$and four $\left(\mathrm{Cbfb}^{\mathrm{f} / \mathrm{f}} \mathrm{Cd} d\right.$-Cre $\left.\mathrm{CD}^{+}\right)$independent samples $(\mathbf{g})$ that were analyzed in $(\mathbf{a}-\mathbf{d}, \mathbf{f})$ two and two to three $(\mathbf{e}, \mathbf{g})$ independent experiments. 